\title{
Design and Validation of the MBW Standard Humidity Generators
}

\section{S. Wettstein ${ }^{1}$ (D) D. Mutter ${ }^{1}$}

Received: 30 October 2016 / Accepted: 13 August 2018 / Published online: 22 August 2018

(c) The Author(s) 2018

\begin{abstract}
MBW Calibration AG (MBW) is the Designated Institute (DI) for humidity appointed by the Federal Institute of Metrology, METAS. MBW currently offers calibration and measurement capabilities (CMC) for frost/dew-point hygrometers by comparison with precision chilled-mirror transfer standards that have been calibrated using the primary standards of leading European National Metrology Institutes or DI. The design, construction and validation of two standard humidity generators to be used as the Swiss national standards for the primary realization of frost/dew-point temperature in the range from $-90{ }^{\circ} \mathrm{C}$ to $+95^{\circ} \mathrm{C}$ are presented and discussed. The generators are operated as continuous flow "single-pressure" generators in the range from $-80^{\circ} \mathrm{C}$ to $-10{ }^{\circ} \mathrm{C}$ with saturation over ice and from $0.5^{\circ} \mathrm{C}$ to $+95^{\circ} \mathrm{C}$ with saturation over water. Additionally, they are used in "two-pressure" mode for saturation over ice down to frost-point temperatures of $-90^{\circ} \mathrm{C}$ and down to $-20^{\circ} \mathrm{C}$ for saturation over water. The main saturators of both generators have been designed to fit in commercially available calibration baths with either ethanol or distilled water as the heat transfer fluid for saturator temperatures below and above $0{ }^{\circ} \mathrm{C}$, respectively. Saturator temperature is measured using standard platinum resistance thermometers and a purpose-built precision thermometer. Pressure measurements are taken with gauge pressure transducers and a separate barometric sensor, to reduce the influence of the atmospheric pressure on the measurement of the pressure ratio and make full use of the correlation of pressure measurements and enhancement factors when operating in two-pressure mode. A totally automated pre-saturation and flow control system facilitates the calibration of state-of-the-art chilled-mirror transfer for standards without manual readjustment of the generated flowrate to ensure a constant volumetric flow at the conditions of the mirror. The uncertainty budget leading to the CMC for frost/dew-point temperature realization is presented in the context of the experimental validation performed. The
\end{abstract}

Selected Papers of the 13th International Symposium on Temperature, Humidity, Moisture and Thermal Measurements in Industry and Science.

S. Wettstein

sascha@mbw.ch; calibration@mbw.ch

1 MBW Calibration AG, Seminarstrasse, 55/57, 5430 Wettingen, Switzerland 
results in the overlapping range of both generators are presented and used as further evidence of the saturation efficiency of both standards.

Keywords Dew point · Frost point · Generator · Humidity standard · Saturation · Saturator efficiency $\cdot$ Water vapor

\section{Introduction}

For several decades, MBW has obtained measurement traceability to the primary realizations of frost/dew-point temperature of leading National Metrology Institutes (NMI), using precision dew-point mirrors (DPM) of its own design, manufactured in its facilities in Wettingen, Switzerland. These have subsequently been used to calibrate customer instruments and other DPMs used for quality control in production using conventional comparison techniques. Since 2011, the technical competence of these calibration activities has been guaranteed via accreditation to [1] by the Swiss Accreditation Body, SAS, as specified in the SCS 125 scope of accreditation [2]. The following years provided the opportunity to further develop the skills in the design and use of DPM transfer standards and to develop standard humidity generators. In 2014, MBW was appointed as the DI in humidity, requiring a primary realization of humidity to be provided at the highest level, commensurate with the needs of the Swiss industry. In 2015, the SCS accreditation was extended to include the primary realization of frost/dew-point temperature in the range from $-20{ }^{\circ} \mathrm{C}$ to $+95{ }^{\circ} \mathrm{C}$ using the MBW high-range generator (HRG). Subsequently, in 2016 it was extended to cover the frost-point temperature realization from below $-20{ }^{\circ} \mathrm{C}$ down to $-90{ }^{\circ} \mathrm{C}$ using the MBW low-range generator (LRG).

This paper describes the operating principles of both generators, the experimental validation of its saturation efficiency, and quantifies the contributions of the measurement uncertainty that justify the calibration and measurement capability (CMC) obtained using the LRG and HRG standard humidity generators, used as the Swiss national humidity standards.

The principles of operation of standard humidity generators based on the definition of the saturation vapor pressure as a function of temperature and the methods used in their experimental validation are well known and have been documented extensively by many NMI and DI [3-6]. This paper concentrates on those aspects necessary to document the LRG and HRG designs, principles of operation, validation tests and justification of the CMC.

\section{Generator Designs and Principle of Operation}

\subsection{General}

\subsubsection{Low-Range Generator}

The LRG saturator (Fig. 1) consists of a stack of five stainless-steel blocks with a machined labyrinth that when primed with ice has a rectangular section for air flow 
through the channels. The channels have two half loops and four complete loops that force the change of direction of the gas flow to ensure adequate contact with the ice surface and enhance saturation efficiency. The repeated changes in direction of the gas flow lead to repeated mixing and hence to an improved saturation efficiency even when operating with dry air with a frost point below $-95^{\circ} \mathrm{C}$. Each flow channel has a height of $10 \mathrm{~mm}$, of which $5 \mathrm{~mm}$ is filled with water (ice), and a width of $8 \mathrm{~mm}$, giving a gas path cross section of $40 \mathrm{~mm}^{2}$ and volume of $29.2 \mathrm{~cm}^{3}$. The total length of all the channels in each block is $755 \mathrm{~mm}$, giving a total path length of $3.775 \mathrm{~m}$, with a total volume of ice of $146 \mathrm{~cm}^{3}$. The stack has a top and bottom endplate for connection to the inlet and outlet. All the saturator elements are welded together to ensure leak tightness. The generator is intended for use as a single-pressure generator where the dry air (or nitrogen) is fully saturated with water vapor over a free ice surface at the saturation temperature. In this mode, the generator operates at a small overpressure with respect to ambient pressure to enable pressure control for the required flowrate. The measured frost point corresponds to the temperature at which the carrier gas was saturated once minor corrections due to the pressure drop in the gas flow have been applied. The generator can also be used in the two-pressure mode by saturation at a higher pressure and subsequently passing the carrier gas through an expansion valve. The generator is essentially an evaporator without a pre-saturator to avoid the possibility of condensation directly in the form of ice that could eventually block the saturator and produce migration of ice crystals through the saturator, that would subsequently evaporate and modify the outlet humidity at the exit of the generator.

Saturator temperature control is achieved using a Hart Scientific model 7080 bath with ethanol as the bath fluid. Air is compressed by an oil-free compressor and dried with a molecular sieve heat-regenerated dryer and increased in pressure using a booster to fill a tank at approximately 1.6 MPa. The air is further dried with another molecular sieve column and passed through two high-purity pressure regulators and fed to the stainless-steel tube to the saturator inlet. The saturated humid air leaves the saturator via a heated stainless-steel tube that is connected to the transfer standard hygrometers via electropolished stainless-steel tubes. When operating in two-pressure mode, the configuration is slightly different. A needle valve assembly is inserted between the outlet and the instruments. The system is configured in such a way that the expansion valve is always purged while not in use and switching between purge and generate modes can be performed easily without ingress of water vapor from ambient. Figure 2 shows the schematic view of the generator and the associated DPM used in the validation tests.

The generator is normally operated with a total flowrate equal to the sum of the individual flowrates of the DPMs plus at least $0.5 \mathrm{~L} \cdot \mathrm{min}^{-1}$ as excess flow in the pressure control loop. The nominal total flowrate is normally $4.5 \mathrm{~L} \cdot \mathrm{min}^{-1}$.

\subsubsection{High-Range Generator}

The HRG consists of three main elements designed and constructed by MBW: (a) A model G1HX humidity generator [7], used as a precision pre-saturator and pressure controller when in two-pressure mode; (b) the HRG main saturator with a heat exchanger and a heated exit manifold; and (c) a motorized expansion valve assembly 


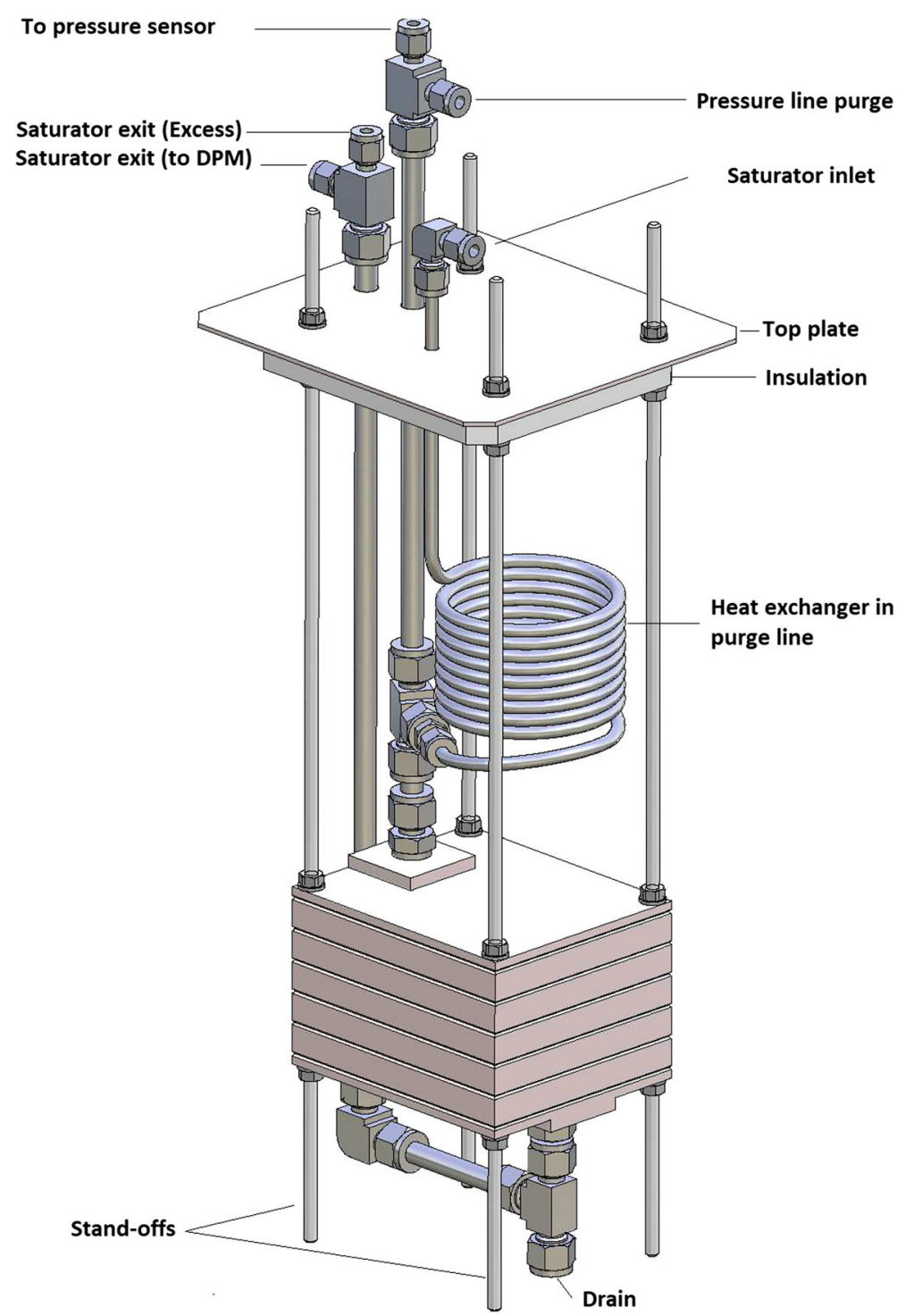

Fig. 1 Schematic of complete LRG saturator assembly with inlet exchanger, bath cover and tubing

connected to the outlet manifold and controlled by the G1HX for saturator pressure control when in two-pressure mode. Saturator temperature control is achieved using a Hart Scientific model 7011 bath with water as the bath fluid. Air is compressed by an oil-free compressor and dried with a molecular sieve heat-regenerated dryer and increased in pressure using a booster to fill a tank at approximately 1.6 MPa. Air is sampled from the tank and the pressure reduced using two pressure regulators and fed to the G1HX pre-saturator and fed via a heated stainless-steel hose to the saturator inlet. The saturated humid air leaves the saturator via a heated manifold that is connected to 


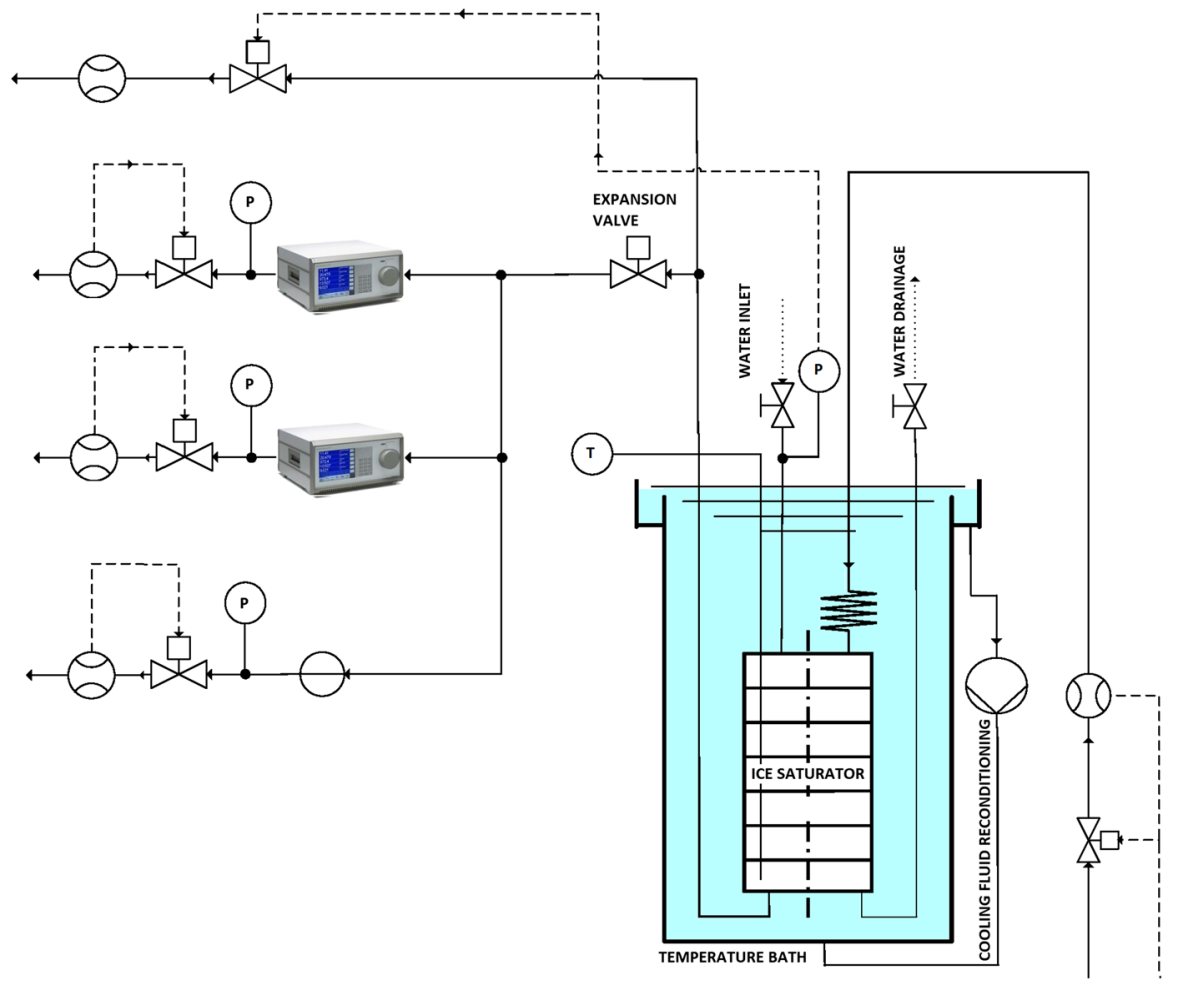

Fig. 2 Schematic view of LRG saturator in generate mode

the transfer standard hygrometers and to a condensation trap, using heated stainlesssteel lines. The outlet of the trap is connected to a diaphragm vacuum pump via a needle valve. This is used to take the excess flow bypassing the hygrometers during the flow-dependence evaluation. When operating in two-pressure mode, a motorized needle valve assembly is inserted between the outlet manifold and the instruments. Figure 3 shows the schematic view of saturator showing heated pre-saturator inlet line and outlet manifold with four sample lines. The main heat exchange and condensate formation occurs in the heat exchanger coil, and condensate falls into the main saturator, leaving only the last few $\mathrm{mK}$ of temperature drop to occur inside the main saturator itself. The heat dissipated during the condensation process helps to ensure that a vertical gradient is maintained such that the main saturator cylinder, closer to the bottom of the bath, is at a slightly lower temperature. This is essential to ensure that the final point of saturation is at a well-defined temperature and pressure. The main saturator is composed of three elements: two solid end caps of outer diameter $89 \mathrm{~mm}$ and a thickness of $35 \mathrm{~mm}$ and a tube of internal diameter $85 \mathrm{~mm}$ and a length of $180 \mathrm{~mm}$, providing a nominal internal volume of approximately $1 \mathrm{~L}$. The mean surface area of the condensate in the bottom of the saturator varies in the range from $50 \mathrm{~cm}^{2}$ to $100 \mathrm{~cm}^{2}$. However, the main saturation surface is in fact the internal surface area of the cylinder (more than four times this), but the vapor pressure will be defined 


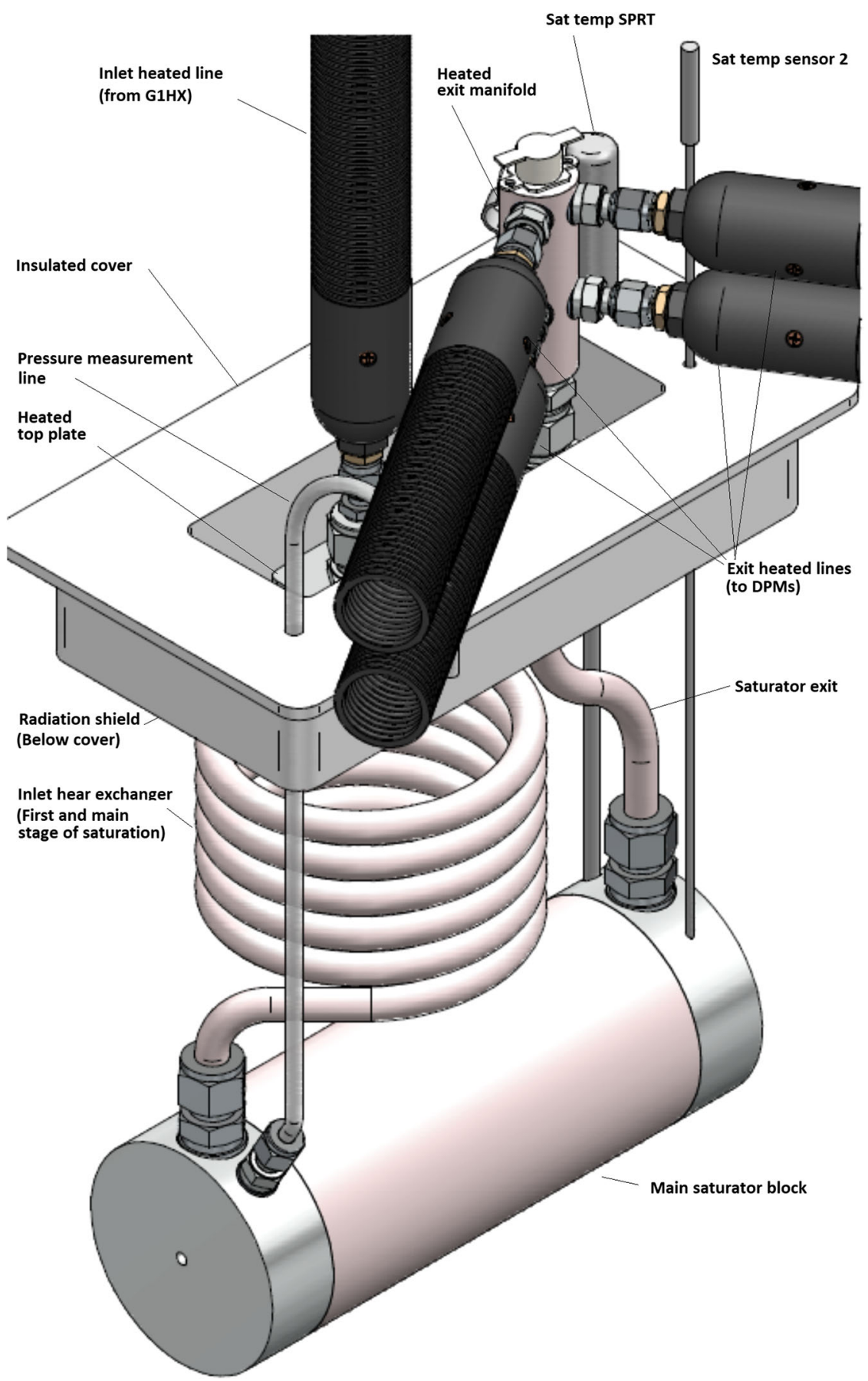

Fig. 3 Schematic view of HRG saturator showing heated pre-saturator inlet line and outlet manifold with four sample lines 
mainly from the flat surface at the bottom of the bath that is estimated to be a few $\mathrm{mK}$ below the wall temperature, just from bath vertical temperature gradients alone (less than $10 \mathrm{mK}$ in $100 \mathrm{~mm}$ ), obtained from temperature measurements in the exit end cap itself. The main thermal mass of the saturator comes from the end caps. There is no special flow conditioning mechanism to ensure the flow path of the gas entering the saturator cylinder as the flowrate dependence tests reported in Sect. 3.3.2 show that the flow regime over the operating range is fit for purpose without any internal conditioning vanes. This simple design is possible because of the existence of the precision pre-saturator that ensures a constant pre-saturation temperature, the first heat exchange coil, together with the excellent bath uniformity and stability and defined gradients due to the layout and bath fluid direction. The warmer bath fluid is directed from the top, back to the bath heat exchange and the cooler bath fluid is directed down to the bottom of the bath where the final saturation cylinder is located. Fluid level is adjusted manually by applying a slight overpressure to the saturator (while purging the pressure measurement lines) and gently bleeding off the condensate via a $4 \mathrm{~mm}$ internal diameter tube connected to the bottom of the saturator at a defined height through a feedthrough in the inlet $35 \mathrm{~mm}$ end cap. Operation over many hours shows that the variation in condensate level is not detectable with the transfer standards used. The schematic of the G1HX generator is given in Fig. 4. Dry air enters passes through a pressure regulator $(\mathrm{PR})$, pressure gauge $(\mathrm{MM})$, the control pressure transmitter $(\mathrm{P} 1)$, a mass flowmeter (MFM), a 2/2 way-proportional valve (V1) and a check valve (V4) before entering the pre-saturator. The air then enters the main saturator of the G1HX and exits via another $2 / 2$ way-proportional valve (V2) and via a heated line to the main saturator. V3 is a $2 / 2$ way solenoid valve (normally open), used to vent the saturator when no power is applied. The pre-saturator of the G1HX is also fitted with a water level sensor. The excess condensate in the G1 HX saturator flows back into the pre-saturator. The design of the G1HX saturator is extensively documented in [8]. Figure 5 shows a photograph of the saturator with a quarter section removed, exposing the six horizontal levels, required to achieve $100 \%$ saturation at a flowrate of $35 \mathrm{~L} \cdot \mathrm{min}^{-1}$ with a pre-saturator temperature $5{ }^{\circ} \mathrm{C}$ above the saturator temperature. The total internal height is $243 \mathrm{~mm}$. The saturator has 11 tubes for heat exchange with the temperature-controlled fluid, as part of the tube-in-shell design. The internal humid gas flow path is shown in Fig. 6, where the vertical flow path (left) and horizontal flow direction (right) are shown. Note the alternate flow direction changes to ensure optimum heat exchange and temperature gradients.

The generator is operated as close as possible to atmospheric pressure as the instruments to be calibrated permit, due to their resistance to flow (internal pressure drop). This will depend on the instrument construction. Typically for an MBW 373HX without internal pump (special configuration for key comparisons), there is an equal pressure drop from inlet to mirror and from mirror to exit. Table 1 shows the summary of operational parameters for the optimum operation of the generator for an individual flowrate of $0.5 \mathrm{~L} \cdot \mathrm{min}^{-1}$ per transfer standard hygrometer. 


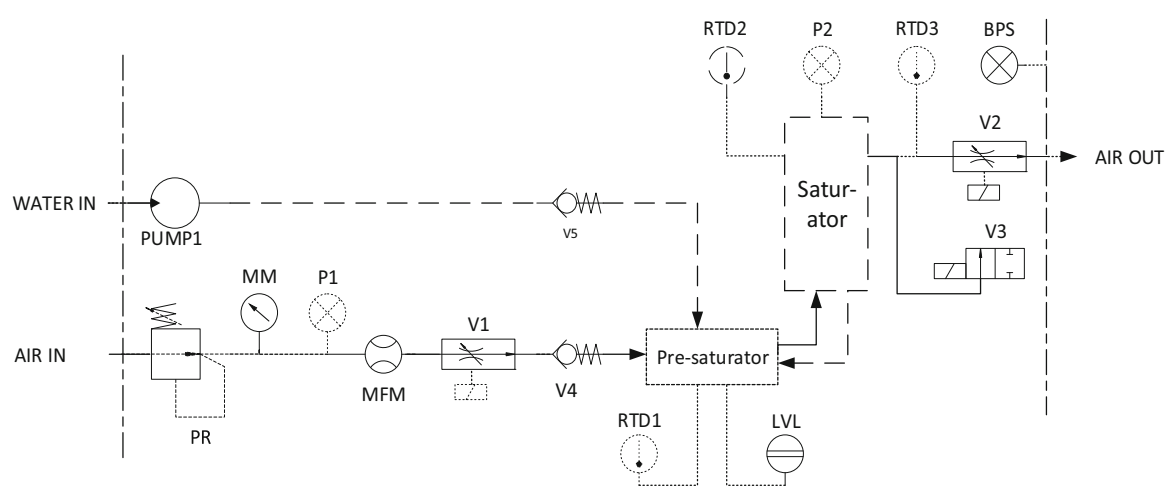

Fig. 4 Schematic of G1HX generator used as the generator pre-saturator and flow control module

Fig. 5 Photograph of G1HX main saturator

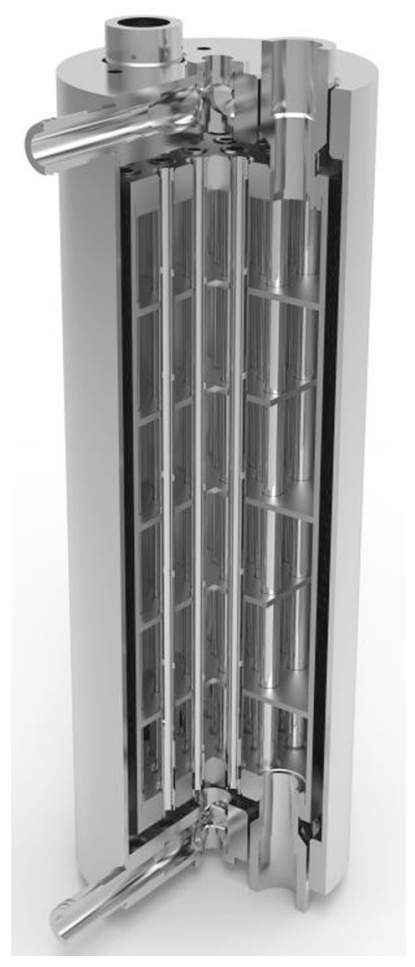

\subsection{Temperature and Pressure Measurement}

Temperature measurement in the main saturator in each generator is performed with two Hart Scientific Model 5626 platinum resistance thermometers. In the LRG, both thermometers are immersed in the bath fluid at different depths close to the exit of the saturator. In the HRG, one is placed in the saturator block at the exit of the saturator and the other is used as a check standard, located in the bath fluid on the saturator exit 

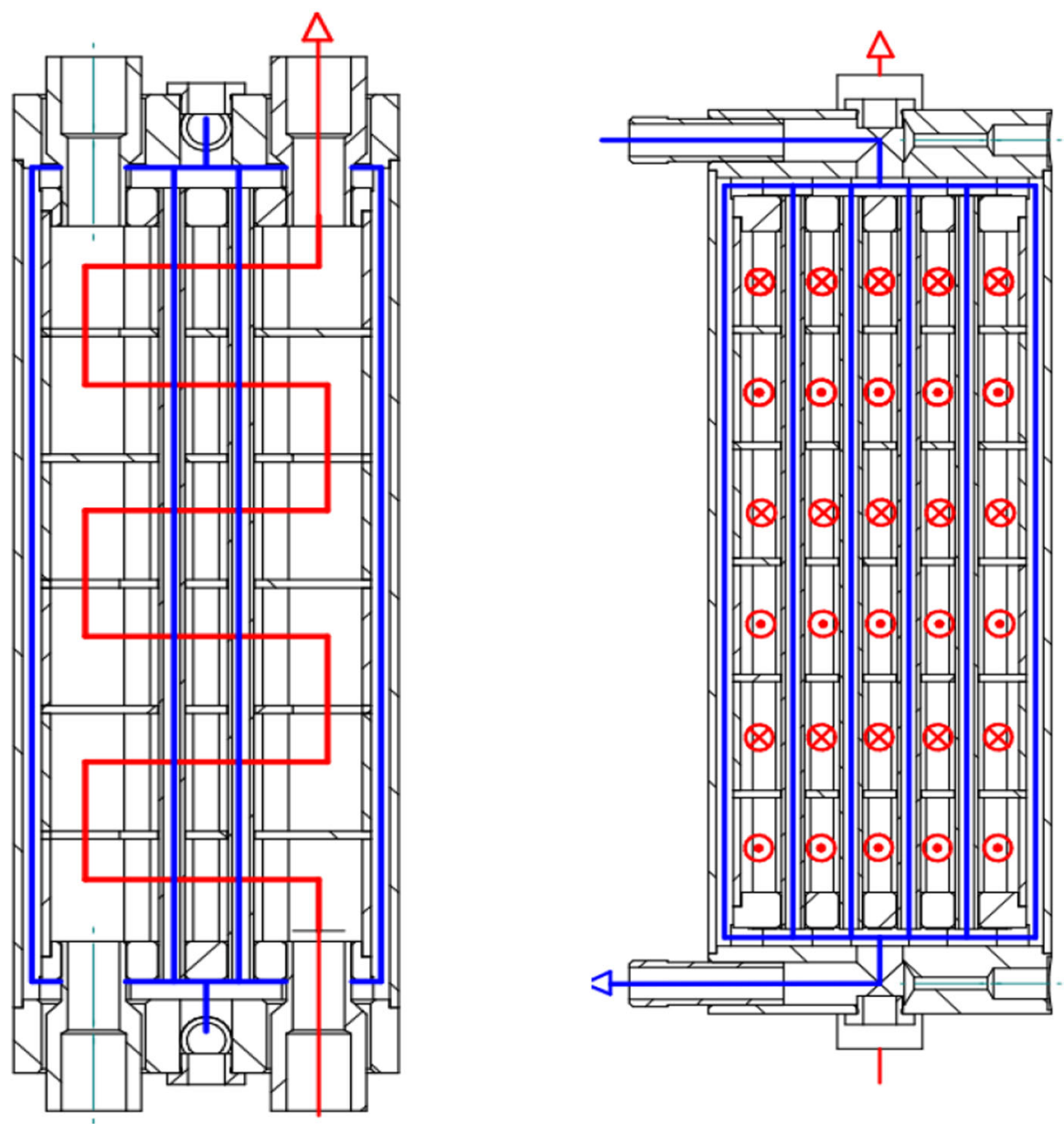

Fig. 6 Schematic of G1HX main saturator showing two sections. On the left the vertical flow path, and on the right the horizontal flow direction

side. This is used to ensure the bath gradient is within the value determined during the initial bath characterization. Additionally, in the LRG, six $3 \mathrm{~mm}$ outer diameter platinum resistance thermometers are placed in the bath fluid around the saturator, covering all the bath volume around the saturator block.

Pressure measurements are taken with three WIKA digital pressure gauges: (a) A model 6100 absolute pressure transmitter; (b) a model 6180, differential pressure transmitter with reference port connected to ambient $(100 \mathrm{kPa}$ and $300 \mathrm{kPa}$ full scale for LRG and HRG, respectively), and (c) a model 6180, 2 MPa differential pressure transmitter. In the LRG, the saturator pressure measuring instruments are connected in a purged line with a larger diameter tube, bypassing the inlet heat exchanger to avoid unwanted sources of water vapor. In the HRG, they are connected via three-way valves that enable purging of the pressure measurement lines during saturator temperature and pressure changes to avoid condensation in the lines. 
Table 1 Summary of operational parameters for the optimum operation of the HRG for an individual flowrate of $0.5 \mathrm{~L} \cdot \mathrm{min}^{-1}$ per hygrometer

\begin{tabular}{lllllllll}
\hline Mode & $\begin{array}{l}\text { FP/DP } \\
\left({ }^{\circ} \mathrm{C}\right)\end{array}$ & $\begin{array}{l}\text { Bath } \mathrm{t} \\
\left({ }^{\circ} \mathrm{C}\right)\end{array}$ & $\begin{array}{l}\text { Pre-sat } \\
\left({ }^{\circ} \mathrm{C}\right)\end{array}$ & $\begin{array}{l}\text { Total flow } \\
\left(\mathrm{L} \cdot \mathrm{min}^{-1}\right)\end{array}$ & $\begin{array}{l}\text { Pre-sat } \\
\text { line } \mathrm{t}_{1} \\
\left({ }^{\circ} \mathrm{C}\right)\end{array}$ & $\begin{array}{l}\text { Heated } \\
\text { plate } \mathrm{t}_{2} \\
\left({ }^{\circ} \mathrm{C}\right)\end{array}$ & $\begin{array}{l}\text { Outlet } \\
\text { manifold } \\
\mathrm{t}_{3}\left({ }^{\circ} \mathrm{C}\right)\end{array}$ & $\begin{array}{l}\mathrm{G} 1 \text { pre-sat } \\
\text { offset }\left({ }^{\circ} \mathrm{C}\right)\end{array}$ \\
\hline $2 \mathrm{P}$ & -20 & 0.35 & 10.0 & 1.0 to 2.0 & 30 & 20 & 30 & $\mathrm{t}+5$ \\
& -10 & & & & & & & \\
$1 \mathrm{P}$ & 0.35 & 0.35 & 25.0 & 1.0 to 2.0 & 30 & 20 & 30 & $\mathrm{t}+5$ \\
& 10 & 10.0 & 25.0 & & 40 & 20 & 45 & $\mathrm{t}+5$ \\
& 20 & 20.0 & 25.0 & & 55 & 25 & 55 & $\mathrm{t}+5$ \\
& 30 & 30.0 & 35.0 & & 60 & 35 & 65 & $\mathrm{t}+5$ \\
40 & 40.0 & 45.0 & & 70 & 45 & 75 & $\mathrm{t}+5$ \\
& 50 & 50.0 & 55.0 & & 80 & 55 & 85 & $\mathrm{t}+5$ \\
60 & 60.0 & 65.0 & & 90 & 65 & 95 & $\mathrm{t}+5$ \\
65 & 65.0 & 70.0 & & 95 & 70 & 95 & $\mathrm{t}+5$ \\
70 & 70.0 & 75.0 & & 100 & 75 & 105 & $\mathrm{t}+5$ \\
75 & 75.0 & 80.0 & & 105 & 80 & 110 & $\mathrm{t}+5$ \\
80 & 80.0 & 85.0 & & 110 & 85 & 115 & $\mathrm{t}+5$ \\
85 & 85.0 & 90.0 & & 115 & 90 & 120 & $\mathrm{t}+5$ \\
90 & 90.0 & 95.0 & & 120 & 95 & 130 & $\mathrm{t}+2$ \\
95 & 95.0 & 95.8 & & 120 & 100 & 130 & $\mathrm{t}+2$ \\
\hline
\end{tabular}

\section{Experimental Validation}

\subsection{General}

The reference condition in the generators is given by the pressure and temperature at the final point of saturation, and hence the saturator temperature and pressure at the outlet as given by the measured inlet pressure corrected for the internal pressure drop and the temperature obtained from the measurement of the reference SPRT (lowest point in the bath close to saturator exit and in the saturator block exit, for the LRG and HRG, respectively).

The influence of the internal pressure drop of the saturator and the gas flowrate dependence has been evaluated experimentally using two MBW transfer standards (373LX and 373HX for the LRG and HRG, respectively). The LRG was evaluated for saturation with respect to ice in both single-pressure mode (frost-point temperatures from $-20{ }^{\circ} \mathrm{C}$ to $-80{ }^{\circ} \mathrm{C}$ ) and two-pressure mode (frost-point temperatures from $-80{ }^{\circ} \mathrm{C}$ to $-90^{\circ} \mathrm{C}$ ). The HRG was evaluated for saturation with respect to water in both single-pressure mode (dew-point temperatures from $0.35^{\circ} \mathrm{C}$ to $95{ }^{\circ} \mathrm{C}$ ) and twopressure mode (frost-point temperatures from $-20{ }^{\circ} \mathrm{C}$ to $-5^{\circ} \mathrm{C}$ ). The pre-saturator temperature dependence was also evaluated for this generator. 


\subsection{Pressure Drops in Saturator and DPMs}

\subsubsection{Low-Range Generator}

The pressure difference between the inlet and outlet of the saturator was determined experimentally using two gauge pressure transmitters. The first $(p 1)$ was connected directly to the inlet throughout the measurements. The second $(p 2)$ was connected to the common port of a 3-way valve with the other two ports connected to the saturator outlet and saturator inlet. This configuration permits sensor alignment at the operating conditions to obtain an accurate determination of the pressure difference, influenced only by the short-term contributions of the pressure transmitters. The method involves three steps that are performed once the stable flow condition has been achieved: (a) the determination of $p 2-p 1$ with both sensors measuring the inlet pressure; (b) the determination of $p 2-p 1$ with $p 1$ measuring the inlet and $p 2$ the outlet; and (c) that is the repetition of (a). The pressure difference is then determined from subtracting the average of the difference obtained in steps (a) and (c) from that obtained in (b).

Measurement of the pressure drops in the DPMs was taken directly with a differential pressure sensor with a 3-way valve connecting the line pressure input to the low-pressure input to perform a sensor zero at the line pressure. Measurements were taken by inserting a tee compression fitting inline and using a special head with pressure measurement port to define the measurement point at the mirror location. Detailed information can be found in [9]. In both cases, the pressure differences were measured at several nominal flowrates over the range of interest, for total generator flow and DPM sample flow, respectively. The results for the LRG saturator are depicted graphically in Fig. 7 as a function of flowrate. The pressure drop increases up to $600 \mathrm{~Pa}$ at a total flow of $10 \mathrm{~L} \cdot \mathrm{min}^{-1}$. This drop needs to be taken into account when determining the saturator absolute pressure from the pressure measurement performed at the inlet. Typical operation of the generator is at $4.5 \mathrm{~L} \cdot \mathrm{min}^{-1}$, producing a pressure drop of approximately $150 \mathrm{~Pa}$. The correct instrument flow is determined from measurements performed with flowmeters connected to the instrument outputs. Prior to commencing measurements, it is necessary to determine the pressure drop of the instrument at the point of reference (either the inlet connection or the mirror, as applicable). At the normal operation flow of $0.5 \mathrm{~L} \cdot \mathrm{min}^{-1}$ to $1.0 \mathrm{~L} \cdot \mathrm{min}^{-1}$, the pressure drop can be in the range from $20 \mathrm{~Pa}$ to $50 \mathrm{~Pa}$, depending on the instrument design. The instrument pressure readings are also used as a cross-check and are aligned with respect to the pressure measurement downstream of the monitoring DPM at zero flow before each calibration run.

\subsubsection{High-Range Generator}

The results for the HRG saturator, using the same method as in the LRG, are depicted graphically in Fig. 8 as a function of flowrate. The pressure drop increases linearly up to $28 \mathrm{~Pa}$ at a total flow of $4 \mathrm{~L} \cdot \mathrm{min}^{-1}$. This drop is considered when determining the saturator absolute pressure from the pressure measurement performed at the inlet. Typical operation of the generator is at $1 \mathrm{~L} \cdot \mathrm{min}^{-1}$ to $2 \mathrm{~L} \cdot \mathrm{min}^{-1}$, for two or four instruments, with a pressure drop of $5 \mathrm{~Pa}$ to $7 \mathrm{~Pa}$. 


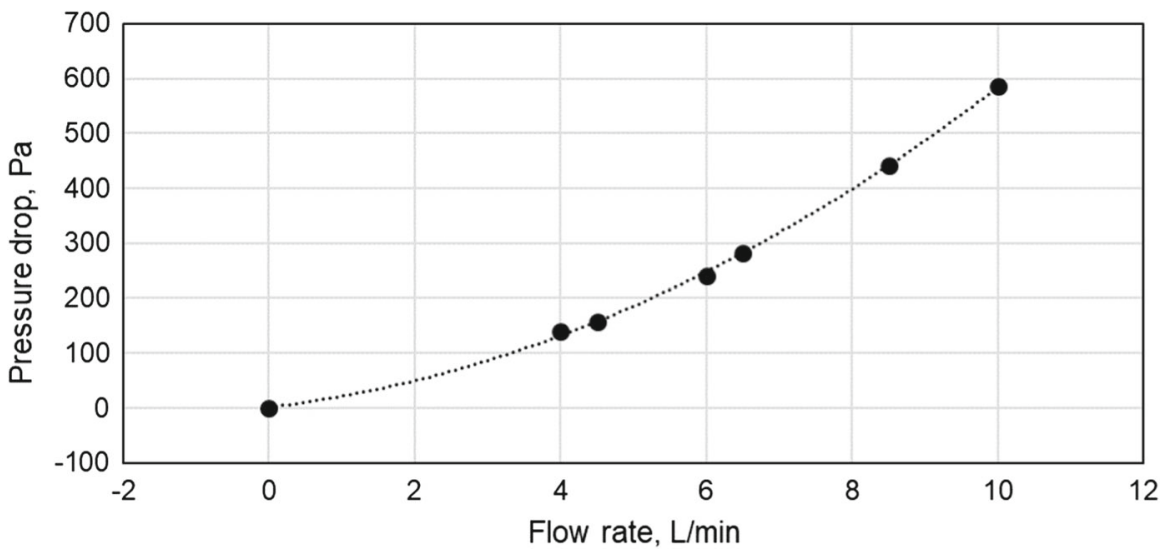

Fig. 7 Pressure drop in LRG saturator as a function of flowrate

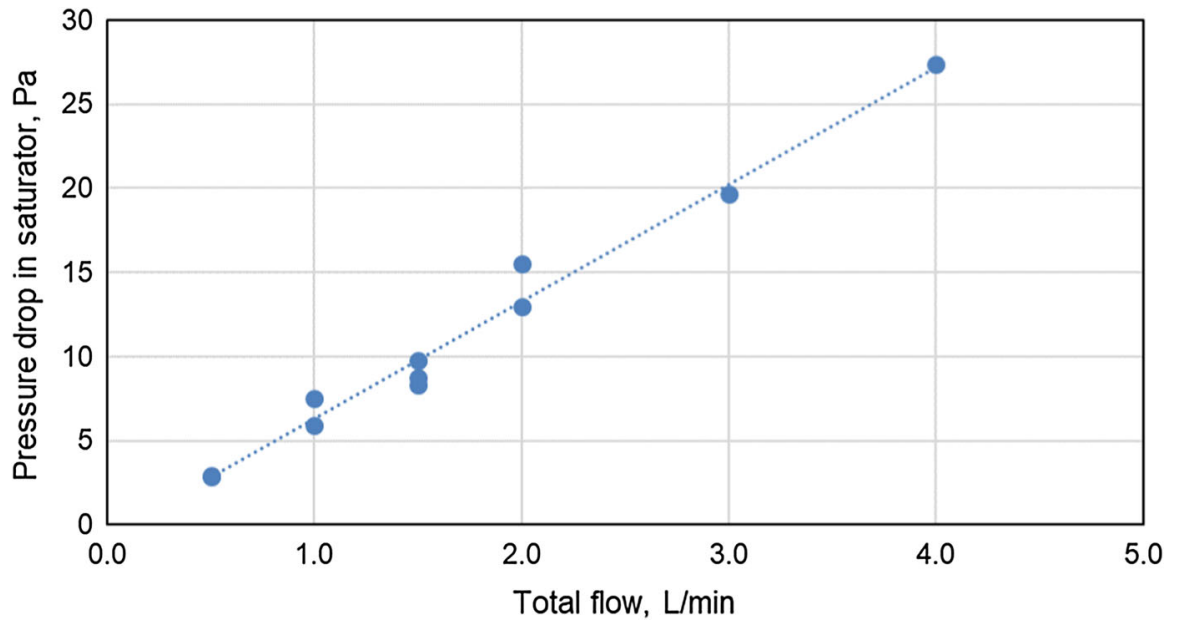

Fig. 8 Pressure drop in HRG main saturator as a function of flowrate

For the HRG, the method employed to fix the flow is different to that usually applied by NMIs and DIs, for example as given in protocols of key comparisons. Normally, these use condensation traps after the transfer standards and measure flow after the traps to set the correct flow through the instruments, as explained in [9]. The method developed at MBW is an empirical approximation developed experimentally to facilitate the automation of the calibration process using the primary generator. We have observed that once the pressure drop in the hygrometer and the ratio of this to the saturator pressure drop have been defined, this only needs to be set up at the beginning and the flow ratio will be maintained to within the limits of reproducibility of the DPMs used in the development of the method. From here on, it is only necessary to fix the gauge pressure at the saturator inlet to the same value, to determine the correct constant volumetric flow at the DPM measuring head conditions (temperature 


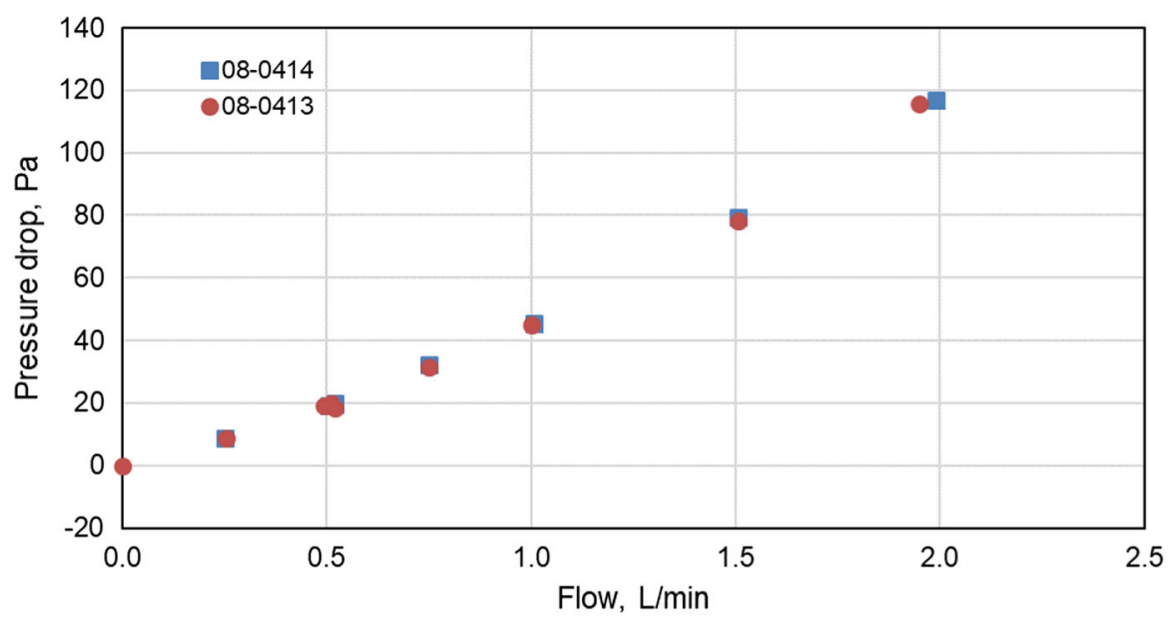

Fig. 9 Instrument measuring head pressure drop to atmosphere as a function of flowrate for the two MBW 373 HX transfer standards with serial numbers 08-0413 and 08-0414

and pressure). For this, the temperature difference between the heated sample line temperature and DPM measuring head temperature with respect to the DPM mirror temperature is fixed (line temperature $=\mathrm{DPM}$ measuring head temperature $=\mathrm{DPM}$ mirror temperature $+30{ }^{\circ} \mathrm{C}$ ). The actual volumetric flowrate can be calculated based on the volume fraction of the wet gas over the mirror at the temperature and pressure using the method defined in this reference. For the HRG, the results can be analyzed in terms of the head pressure drop to atmosphere and the ratio to the saturator gauge pressure measured at the inlet as a function of the flow through the instruments. The correct instrument flow is determined from measurements performed at $20{ }^{\circ} \mathrm{C}$. It is necessary to measure the pressure drop of the instrument at the point of reference (either the inlet connection to the DPM or the mirror, as applicable). Figure 9 shows the measured pressure drop from the head to atmosphere for the two MBW 373HX instruments used in the validation of the generator (serial numbers 08-0413 and 080414). As can be seen, at the normal operation flow of $0.5 \mathrm{~L} \cdot \mathrm{min}^{-1}$, the pressure drop is $20 \mathrm{~Pa}$ and the flow dependence of both instruments is identical, as expected for instruments of the same dimensions. This is the internal pressure drop from the mirror to atmosphere at the given flowrate. The ratio of the hygrometer gauge head pressure to saturator inlet gauge pressure as a function of flowrate is shown in Fig. 10 for both transfer standards.

\subsection{Flow-Dependence Tests}

\subsubsection{Low-Range Generator}

Single-Pressure Mode The tests were performed at bath temperatures of $-20{ }^{\circ} \mathrm{C}$, $-60{ }^{\circ} \mathrm{C}$ and $-80{ }^{\circ} \mathrm{C}$ for total airflow from $4 \mathrm{~L} \cdot \mathrm{min}^{-1}$ to $10.5 \mathrm{~L} \cdot \mathrm{min}^{-1}$ at the points given in Table 2. The volumetric flow through the DPMs was kept at $0.5 \mathrm{~L} \cdot \mathrm{min}^{-1}$ down 


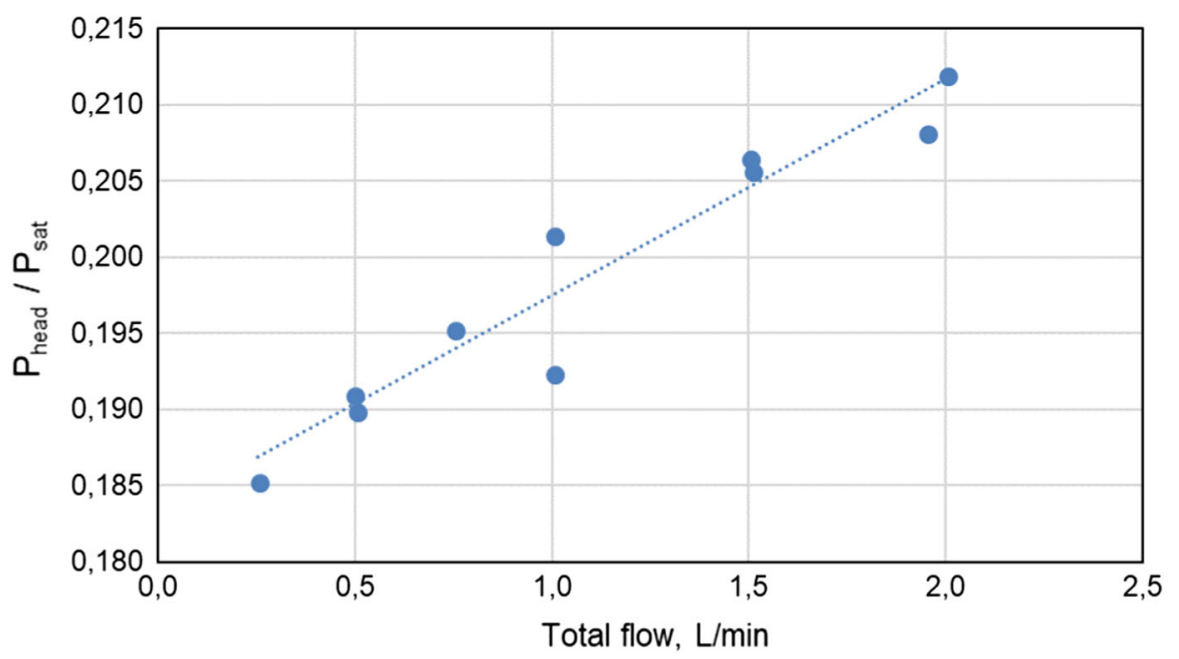

Fig. 10 Ratio of DPM measuring head gauge pressure to HRG inlet sat gauge pressure for the two MBW 373 HX transfer standards with serial numbers 08-0413 and 08-0414

Table 2 Flowrate dependence test points for LRG

\begin{tabular}{llll}
\hline Mode & FP $\left({ }^{\circ} \mathrm{C}\right)$ & Bath $\left({ }^{\circ} \mathrm{C}\right)$ & Total flow $\left(\mathrm{L} \cdot \mathrm{min}^{-1}\right)$ \\
\hline $1 \mathrm{P}$ & -20 & -20 & $4,6,10,4$ \\
& -60 & -60 & $4.5,6.5,4.5,8.5,4.5$ \\
& -80 & -80 & $4.5,6.5,8.5,10.5$ \\
$2 \mathrm{P}$ & -90 & -80 & $4.5,6.5,8.5,10.5,4.5$
\end{tabular}

to $-60{ }^{\circ} \mathrm{C}$ and $1.0 \mathrm{~L} \cdot \mathrm{min}^{-1}$ below. Figure 11 shows the results of the study of the effect of flowrate on the instrument corrections for both transfer standards at a nominal frost-point temperature of $-20^{\circ} \mathrm{C}$. The difference is less than $\pm 4 \mathrm{mK}$ over the range with a variation of less than $+0.8 \mathrm{mK} \cdot \mathrm{L}^{-1} \cdot \mathrm{min}^{-1}$. The results of the study at a nominal frost-point temperature of $-60{ }^{\circ} \mathrm{C}$ showed a variation of less than $\pm 6 \mathrm{mK}$ over the range with a difference of less than $-1.9 \mathrm{mK} \cdot \mathrm{L}^{-1} \cdot \mathrm{min}^{-1}$. Similarly, the results of the study at $-80^{\circ} \mathrm{C}$, the lower limit in $1 \mathrm{P}$ mode, the obtained variation is less than $\pm 5 \mathrm{mK}$ for flowrates up to $8.5 \mathrm{~L} \cdot \mathrm{min}^{-1}$ with a slope less than $-2.2 \mathrm{mK} \cdot \mathrm{L}^{-1} \cdot \mathrm{min}^{-1}$. At $10.5 \mathrm{~L} \cdot \mathrm{min}^{-1}$, the effect is double.

Two-Pressure Mode Two-pressure mode is used for generating nominal frost-point temperatures below the lowest bath temperature $\left(-80^{\circ} \mathrm{C}\right)$. Tests were performed at a nominal frost-point temperature of $-90^{\circ} \mathrm{C}$ with the saturator at a nominal temperature of $-80^{\circ} \mathrm{C}$. This corresponds to a maximum saturator absolute pressure of $600 \mathrm{kPa}$. In the frost-point temperature range between $-100{ }^{\circ} \mathrm{C}$ and $0{ }^{\circ} \mathrm{C}$, the uncertainty associated with the enhancement factor is a strong function of pressure and temperature and it is important to keep the saturator pressure as low as possible to keep the uncertainty due to the enhancement factors as low as possible $[10,11]$. For example, at $-80^{\circ} \mathrm{C}$, the standard uncertainty in the enhancement factor [10] is $0.05 \%, 0.26 \%$ and $0.5 \%$ 


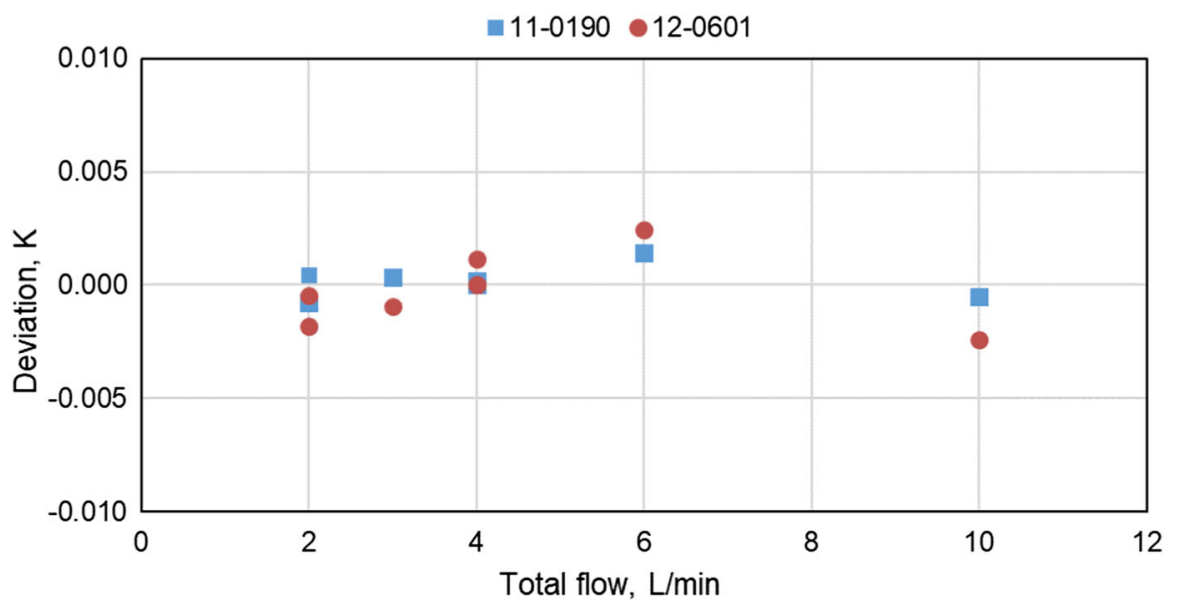

Fig. 11 Variation of instrument correction as a function of flowrate at $-20{ }^{\circ} \mathrm{C}$ frost-point temperature for two MBW 373LX transfer standards from $2 \mathrm{~L} \cdot \mathrm{min}^{-1}$ to $10 \mathrm{~L} \cdot \mathrm{min}^{-1}$ on LRG. Y-axis is the deviation from the value measured at $4 \mathrm{~L} \cdot \mathrm{min}^{-1}$

at saturation pressures of $0.1 \mathrm{MPa}, 0.5 \mathrm{MPa}$ and $1.0 \mathrm{MPa}$, respectively. The saturation water vapor and enhancement factor values have been determined from [12].

Figure 12 shows the results of the study of the effect of flowrate on the instrument corrections, for both transfer standards at the nominal frost-point temperature of $-90{ }^{\circ} \mathrm{C}$. The graph shows the difference with respect to the first reading at a nominal flow of $4.5 \mathrm{~L} \cdot \mathrm{min}^{-1}$ for both DPMs. For DPM serial numbers 11-0190 and 12-0601, the values at $4.5 \mathrm{~L} \cdot \mathrm{min}^{-1}$ vary from $42 \mathrm{mK}$ to $-32 \mathrm{mK}$ and from $0 \mathrm{mK}$ to $-82 \mathrm{mK}$, respectively. The difference then increases with a slope of $-4.5 \mathrm{mK} \cdot \mathrm{L}^{-1} \cdot \mathrm{min}^{-1}$ and $-6.8 \mathrm{mK} \cdot \mathrm{L}^{-1} \cdot \mathrm{min}^{-1}$ up to a flowrate of $10.5 \mathrm{~L} \cdot \mathrm{min}^{-1}$ for $11-0190$ and $12-0601$, respectively.

\subsubsection{High-Range Generator}

Single-Pressure Mode The generator was configured in single-pressure mode. The tests were performed at bath temperatures of $95^{\circ} \mathrm{C}, 90^{\circ} \mathrm{C}, 70^{\circ} \mathrm{C}, 20^{\circ} \mathrm{C}$ and $0.35^{\circ} \mathrm{C}$ for total airflow from $1 \mathrm{~L} \cdot \mathrm{min}^{-1}$ to $5 \mathrm{~L} \cdot \mathrm{min}^{-1}$ for a constant volumetric flow of $0.5 \mathrm{~L} \cdot \mathrm{min}^{-1}$ at the conditions of the mirrors in the two transfer standards used.

Figure 13 shows the results of the study of the effect of flowrate on the instrument corrections for both transfer standards at nominal dew-point temperatures of $0.35^{\circ} \mathrm{C}$, $20{ }^{\circ} \mathrm{C}, 90{ }^{\circ} \mathrm{C}$ and $95{ }^{\circ} \mathrm{C}$. The variation is less than $\pm 10 \mathrm{mK}$ over the range. The dotted line represents a slope of $2 \mathrm{mK} \cdot \mathrm{L}^{-1} \cdot \mathrm{min}^{-1}$, showing that the measured output decreases very slightly with the generated flowrate. This a most satisfactory result, consistent with moderate internal pressure drops and their uncertainty and evidence of saturation efficiency. The test points measured are given in Table 3. 


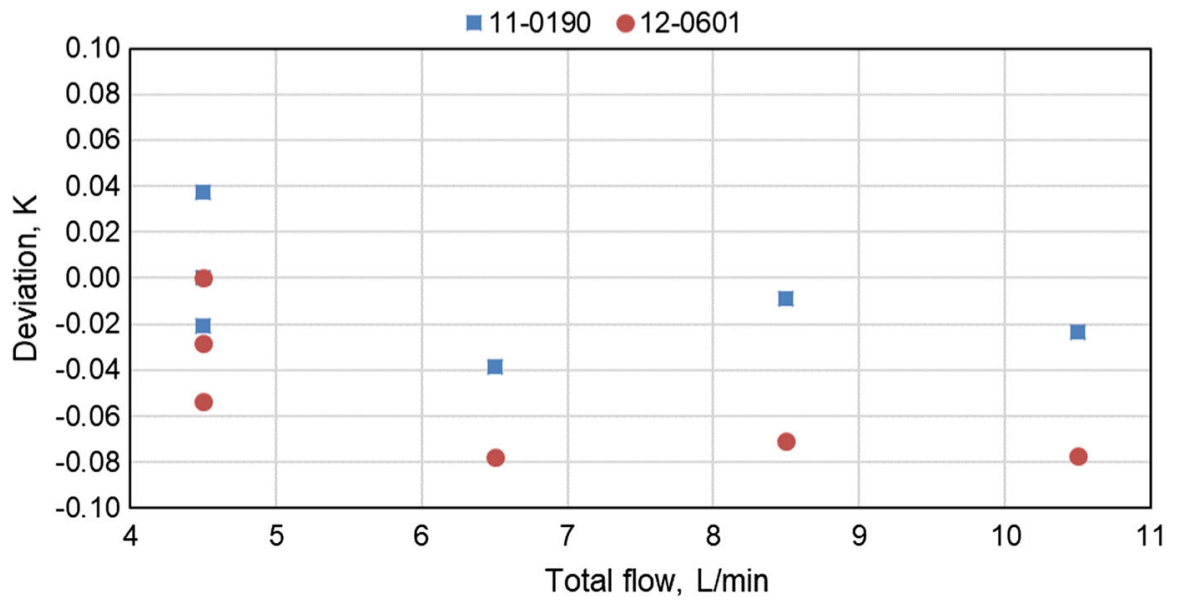

Fig. 12 Variation of instrument correction as a function of flowrate at $-90{ }^{\circ} \mathrm{C}$ frost-point temperature for two MBW 373LX transfer standards from $4.5 \mathrm{~L} \cdot \mathrm{min}^{-1}$ to $10.5 \mathrm{~L} \cdot \mathrm{min}^{-1}$. Y-axis is the deviation from the value measured at $4 \mathrm{~L} \cdot \mathrm{min}^{-1}$

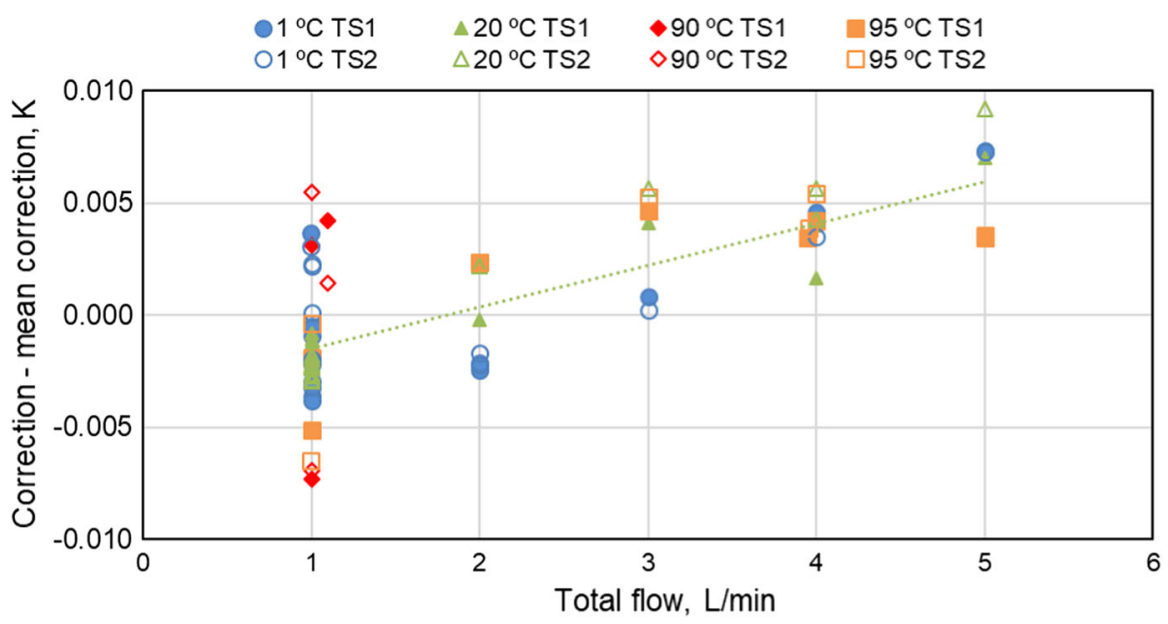

Fig. 13 Variation of instrument correction as a function of flowrate at $0.35{ }^{\circ} \mathrm{C}, 20{ }^{\circ} \mathrm{C}, 90{ }^{\circ} \mathrm{C}$ and $95{ }^{\circ} \mathrm{C}$ dew-point temperatures for both units

Two-Pressure Mode The generator was configured in two-pressure mode with the external motorized expansion valve. Tests were performed at nominal frost-point temperatures of $-5{ }^{\circ} \mathrm{C},-10{ }^{\circ} \mathrm{C}$ and $-20{ }^{\circ} \mathrm{C}$, with a saturator at a nominal temperature of $0.35{ }^{\circ} \mathrm{C}$. This corresponds to a maximum saturator absolute pressure of $600 \mathrm{kPa}$. The range of values covers the complete range to be used with water as the bath fluid and to keep the uncertainty low in as much as enhancement factors are concerned at this moderate saturator pressure $[10,11]$. The saturation water vapor values have been determined from [12]. 
Table 3 Flowrate dependence test points for HRG

\begin{tabular}{lllll}
\hline Mode & FP/DP $\left({ }^{\circ} \mathrm{C}\right)$ & Bath $\left({ }^{\circ} \mathrm{C}\right)$ & Pre-sat $\left({ }^{\circ} \mathrm{C}\right)$ & $\begin{array}{l}\text { Total flow } \\
\left(\mathrm{L} \cdot \mathrm{min}^{-1}\right)\end{array}$ \\
\hline $1 \mathrm{P}$ & 95 & 95 & 96 & 1,5 \\
& 95 & 95 & 95.8 & $1,2,3,4,5$ \\
& 90 & 90 & 91 & 1,2 \\
& 70 & 70 & 71 & $1,2,3,4,5$ \\
& 20 & 20 & 21 & $1,2,3,4,5$ \\
& 0.35 & 0.35 & 10 & $1,2,3,4,5$ \\
$2 \mathrm{P}$ & -5 & 0.35 & 15 & 1,5 \\
& -20 & 0.35 & 22 & $1,2,4,5$ \\
\hline
\end{tabular}

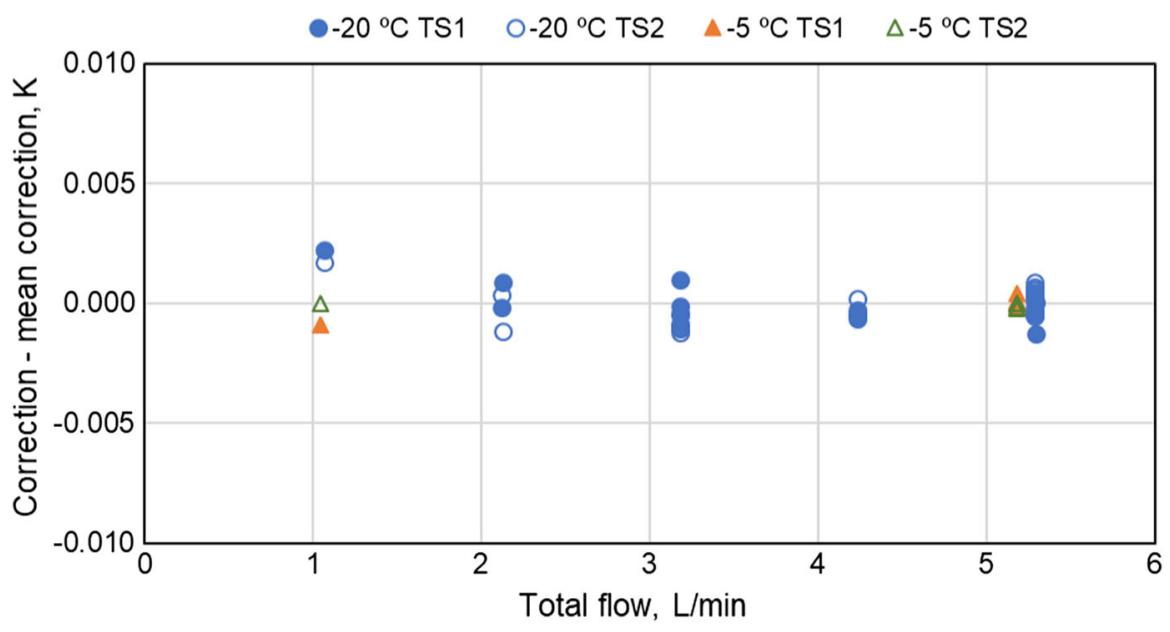

Fig. 14 Variation of instrument correction as a function of flowrate at $-20{ }^{\circ} \mathrm{C}$ and $-5{ }^{\circ} \mathrm{C}$ frost-point temperatures for both transfer standards

Figure 14 shows the results of the study of the effect of flowrate on the instrument corrections, for both transfer standards at nominal frost-point temperatures of $-20^{\circ} \mathrm{C}$, and $-5^{\circ} \mathrm{C}$. As can be seen, the variation is less than $\pm 3 \mathrm{mK}$ over the range. The test points are given in Table 3.

\subsection{Pre-saturator Temperature Dependence Tests}

\subsubsection{High-Range Generator}

Single-Pressure Mode For optimal performance of the generator, it is necessary to ensure that there is enough condensate in the main saturator to provide the necessary wet surface area to obtain $100 \%$ saturation of the gas during its lingering time in the saturator. On the other hand, it is necessary to limit the total amount of condensate so that the water level in the saturator does not restrict the available cross section for gas 


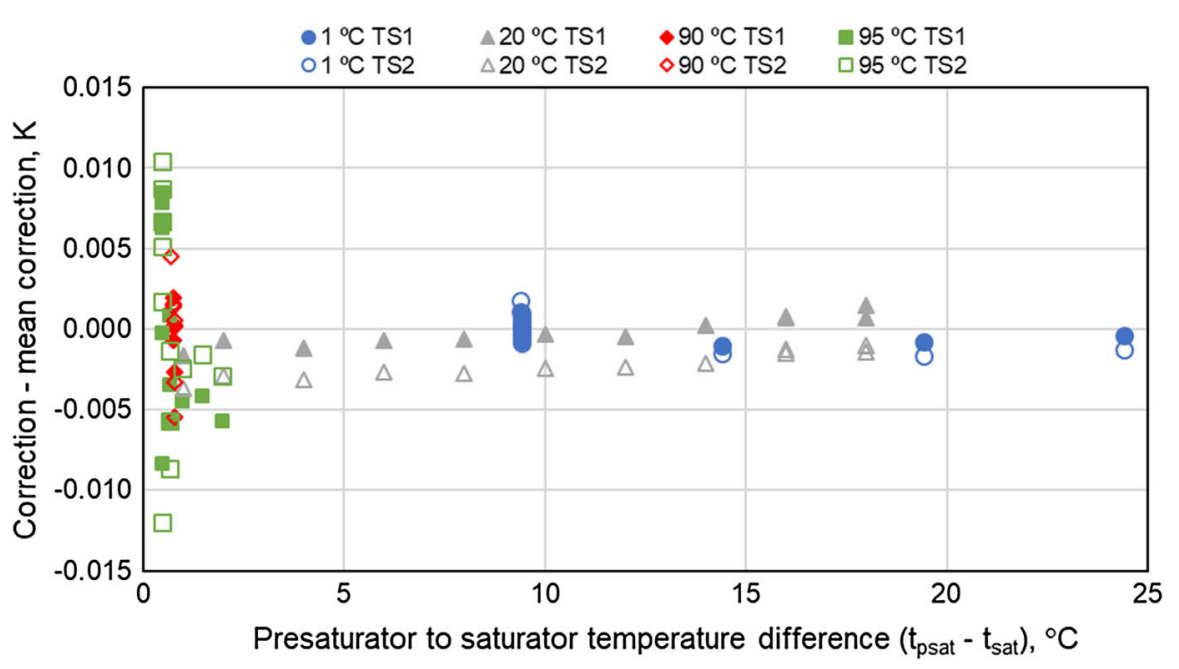

Fig. 15 Variation of instrument correction as a function of pre-saturator to saturator differential at $0.35{ }^{\circ} \mathrm{C}$, $20^{\circ} \mathrm{C}, 90^{\circ} \mathrm{C}$ and $95^{\circ} \mathrm{C}$ dew-point temperatures for both units

flow in such a way that the pressure drop within the saturator is kept within the operational limits of the evaluation performed. The dependence of the generated dew-point temperature on the pre-saturator temperature differential, defined as the temperature difference between the pre-saturator temperature (generated dew-point temperature of $\mathrm{G} 1 \mathrm{HX}$ ) and the main saturator temperature, was evaluated experimentally up to the upper limit of pre-saturator temperature in the range $t d+0.35$ to $t d+95^{\circ} \mathrm{C}$. The variation of instrument correction (realized dew-point temperature-DPM reading) minus mean instrument correction, as a function of pre-saturator to saturator temperature differential at $0.35^{\circ} \mathrm{C}, 20{ }^{\circ} \mathrm{C}, 90^{\circ} \mathrm{C}$ and $95^{\circ} \mathrm{C}$ dew-point temperatures for both transfer standards, is depicted in Fig. 15. The ordinate shows the difference with respect to the mean instrument correction to enable graphical representation. As can be seen, the variation is less than $\pm 5 \mathrm{mK}$ over the range up to $90{ }^{\circ} \mathrm{C}$ and within $\pm 13 \mathrm{mK}$ at $95^{\circ} \mathrm{C}$, shown as circles and triangles, respectively. The test points are given in Table 4.

Two-Pressure Mode The variation of instrument correction minus mean instrument correction, as a function of pre-saturator to saturator temperature differential at $-20{ }^{\circ} \mathrm{C},-10{ }^{\circ} \mathrm{C}$ and $-5{ }^{\circ} \mathrm{C}$ frost-point temperatures for both transfer standards, is depicted in Fig. 16. As can be seen, the variation is less than $\pm 3 \mathrm{mK}$ over the range. The test points are given in Table 4.

\section{Calibration and Measurement Capability}

\subsection{Contributions to the Measurement Uncertainty in Frost/Dew-Point Temperature Realization}

Based on the experimental determination reported in the previous sections, the values of the estimates of the individual components of uncertainty for the different mea- 
Table 4 Pre-saturator dependence test points for HRG

\begin{tabular}{lllll}
\hline Mode & FP/DP $\left({ }^{\circ} \mathrm{C}\right)$ & Bath $\left({ }^{\circ} \mathrm{C}\right)$ & Pre-sat $\left({ }^{\circ} \mathrm{C}\right)$ & $\begin{array}{c}\text { Total flow } \\
\left(\mathrm{L} \cdot \mathrm{min}^{-1}\right)\end{array}$ \\
\hline $1 \mathrm{P}$ & 95 & 95 & $91,94,95.8,96.3,96.8$, & 1 \\
& 90 & 90 & 97.3 & 1 \\
& 70 & 70 & $91,92,93,94,95$ & 1 \\
& & & $71,72,74,76,78,80,82$, & \\
& 20 & 20 & 84,90 & 1 \\
& & & $21,22,24,26,28,30,32$, & \\
& 0.35 & 0.35 & $10,15,20,25$ & 1 \\
& -5 & 0.35 & 15 & 5 \\
& -5 & 0.35 & $10,15,25,30,35$ & 1 \\
& -10 & 0.35 & $10,15,20$ & 1 \\
& -20 & 0.35 & $10,12,14,18,22$ & 5 \\
\hline
\end{tabular}

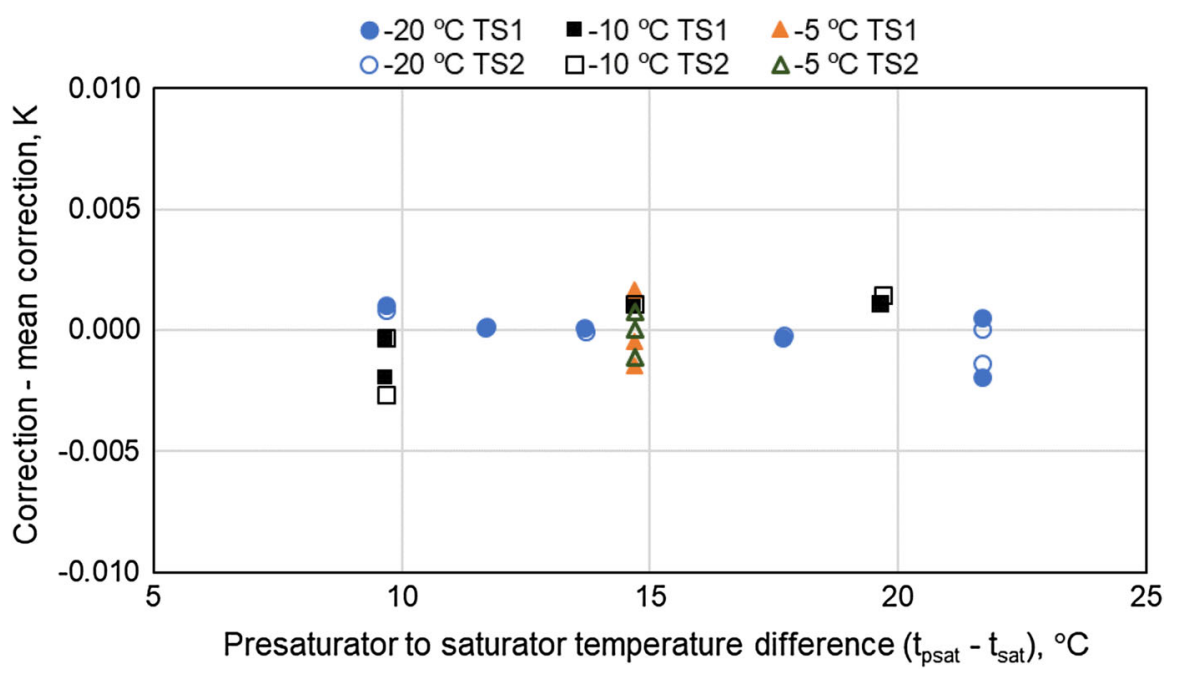

Fig. 16 Variation of instrument correction as a function of pre-saturator to saturator differential at $-20{ }^{\circ} \mathrm{C}$, $-10{ }^{\circ} \mathrm{C}$ and $-5^{\circ} \mathrm{C}$ frost-point temperatures for both transfer standards

surement quantities have been determined and used in the calculation of the CMC. Table 5 lists the main contributions of uncertainty in the determination of the generated reference frost/dew-point temperature. The three main groups encompass the type-A and type-B contributions as follows: (a) contributions due to the measurement of the saturation temperature, ts (defined at the saturator exit, considered the final point of saturation); (b) contributions due to the measurement of the saturation pressure, ps (also defined at the saturator exit) and (c) Gas pressure at the DPM (necessary to calculate the reference frost/dew-point at the DPM mirror). 
Table 5 List of contributions to the measurement uncertainty in frost/dew-point temperature realization using standard humidity generators

\begin{tabular}{ll}
\hline Quantity (symbol) Qi & Component \\
\hline Saturation temperature, ts, at saturator exit & Thermometer \\
& Calibration uncertainty (sensor and indicator unit) \\
$t s \_c a l$ & Long-term stability (sensor and indicator) \\
$t s \_d r i f t$ & Self-heating and residual heat fluxes (sensor) \\
$t s \_s h$ & Resolution and accuracy or linearity (indicator unit) \\
$t s \_r e s$ & Saturator \\
& Temperature homogeneity (at SPRT measurement point) \\
$t s \_h o m$ & Temperature stability
\end{tabular}

Saturation pressure, Ps. Absolute pressure at saturator exit

Pressure gauge

$\begin{array}{ll}P s \_c a l & \text { Calibration uncertainty (sensor and indicator unit) } \\ P s \_d r i f t & \text { Long-term stability (sensor and indicator) } \\ P s \_t c & \text { Temperature coefficient } \\ P s \_r e s & \text { Resolution and accuracy or linearity (indicator unit) } \\ P s \_g r a d & \text { Pressure differences in the saturator cell } \\ P s \_s t a b & \text { Stability of the pressure (standard deviation of } 60 \text { readings) } \\ P s \_t u b & \text { Effect of the tubing between the saturator and pressure gauge }\end{array}$

Gas pressure at DPM, Pd

Pressure gauge

Pd_cal Calibration uncertainty (sensor and indicator unit)

$P d$ _drift Long-term stability (sensor and indicator)

$P d \_t c \quad$ Temperature coefficient

$P d \_$res $\quad$ Resolution and accuracy or linearity (indicator unit)

$P d \_s t a b \quad$ Stability of the pressure (standard deviation of 60 readings)

$P d \_t u b \quad$ Effect of the tubing between the saturator and pressure gauge

Saturation efficiency

Saturation efficiency (included in saturation temperature)

Correlation between pressure and temperature measurement (if relevant)

Not relevant

Uncertainty due to formulae/calculations (applicable in 2P mode only)

es

$f s$

ed

$f d$
Saturation vapor pressure formula(e) at ts

Water vapor enhancement formula(e) at ts, Ps

Saturation vapor pressure formula(e) at td

Water vapor enhancement formula(e) at td, Pd

The saturation efficiency is in fact included in the saturation temperature contributions and validated via the flow and pre-saturator dependence tests reported. Correlation between saturator pressure and temperature measurement is not consid- 
ered relevant due to the excellent stability in both measurement quantities, that make this influence negligible compared to other contributions of the budget. The case of the contributions due to the uncertainty of the formulae/calculations of the saturation vapor pressure (es and $e d$ ) and enhancement factors ( $f s$ and $f d$ ) is only relevant in the two-pressure mode, and especially for measurements in the LRS where $2 \mathrm{P}$ measurements are necessary due to achieve frost-point temperatures below the lower bath temperature limit of $-80{ }^{\circ} \mathrm{C}$. They are the limiting factor in the $2 \mathrm{P}$ mode. The estimation of these contributions and the reduction due to correlation are taken from [10-13].

In both generators, the temperature sensors used are calibrated by comparison in liquid baths with externally calibrated SPRTs that have been calibrated at the ITS90 fixed points. The value of $t s \_c a l$ obtained is $5 \mathrm{mK}(k=1)$ [2]. The platinum resistance thermometer sensors and precision thermometer (MBW model T12) used for the measurement of their resistance and conversion to temperature are calibrated as a system. The value of $t s \_d r i f t$ is determined from the calibration history and is estimated to be less than $5 \mathrm{mK} \cdot \mathrm{year}^{-1}$. This is treated as a rectangular distribution. Regular determination of the resistance at the triple point of water is performed of the combined system. Ts_sh is very small because the T12 thermometer measures in a pulsed mode and the T12 and sensor are both calibrated and used in similar conditions in stirred liquid baths with equilibration block. The value is estimated to be less than $1 \mathrm{mK}$, treated also as a rectangular distribution. Ts_res is the combined resolution, and accuracy of the T12 thermometer through internal calibration with precision resistors is shown to be within $2 \mathrm{mK}$, treated also as a rectangular distribution.

The calibration of the platinum resistance thermometer sensors and the MBW model T12 thermometer used for the measurement of their resistance and conversion to temperature are those given in [2]. Their long-term stability is obtained from their calibration history, and the drift is minimized using the current value of the resistance obtained at the triple point of water, measured with the same T12 thermometer. This builds in the combined drift of the sensor and resistance measuring device.

Tables 6 and 7 show the values of the contributions of $t s \_h o m, t s \_s t a b p s \_s t a b$ and ps_stab, for the complete range in the two operational modes for the LRG and HRG standard humidity generators, respectively. The values of temperature homogeneity (ts_hom) are obtained experimentally from the maximum difference between the mean values of the two measured saturator temperatures. In the case of stability, they are the maximum allowed standard deviation of temperature $\left(t s \_s t a b\right)$ or pressure ( $p s \_s t a b$, td_stab) measurements.

The contributions due to the calibration of the pressure sensors ( $P s \_c a l$ and $P d \_c a l$ ) are obtained from the external calibrations (the calibration uncertainty is less than one quarter of the instrument 12-month specification), and contribution due to the long-term stability ( $P s \_d r i f t$ and $P d \_d r i f t$ ) is the instrument 12-month specification and corroborated via the instrument calibration history. The resolution and linearity (Ps_res) are obtained from the manufacturer's specification and the analysis of the calibration results. The temperature coefficient of the pressure gauges $P s \_t c$ and $P d \_t c$ ) is taken from the manufacturer's 12-month specification. The gauge sensors are checked regularly using a Ruska 2465 pressure balance and the absolute pressure sensors are checked against each other. The external calibration intervals of the absolute pres- 
Table 6 Uncertainty contributions for temperature and pressure measurements in LRG, used to determine the CMC. The stability is given as one standard deviation and the homogeneity as the gradient obtained from the two temperature measurements

\begin{tabular}{|c|c|c|c|c|}
\hline Mode & $\begin{array}{l}\text { Parameter } \\
\text { (see Table 5) }\end{array}$ & Saturator temperature range & Sensor & Value \\
\hline \multirow[t]{2}{*}{$1 \mathrm{P} / 2 \mathrm{P}$} & $t s \_s t a b$ & $\begin{array}{l}-80^{\circ} \mathrm{C} \leq \mathrm{t} \leq-60^{\circ} \mathrm{C} \\
-60^{\circ} \mathrm{C} \leq \mathrm{t} \leq-20^{\circ} \mathrm{C}\end{array}$ & $\begin{array}{l}\text { Saturator } \\
\text { temperature }\end{array}$ & $\begin{array}{l}10 \mathrm{mK} \\
5 \mathrm{mK}\end{array}$ \\
\hline & ts_hom & $\begin{array}{l}-80^{\circ} \mathrm{C} \leq \mathrm{t} \leq-60^{\circ} \mathrm{C} \\
-60^{\circ} \mathrm{C} \leq \mathrm{t} \leq-20^{\circ} \mathrm{C}\end{array}$ & $\begin{array}{l}\text { Saturator } \\
\text { temperature }\end{array}$ & $\begin{array}{l}15 \mathrm{mK} \\
10 \mathrm{mK}\end{array}$ \\
\hline $2 \mathrm{P}$ & $\begin{array}{l}P s \_s t a b \\
P d \_s t a b\end{array}$ & $-80^{\circ} \mathrm{C} \leq \mathrm{t} \leq-20^{\circ} \mathrm{C}$ & $\begin{array}{l}\text { High range } \\
\text { Low range } \\
\text { Barometric }\end{array}$ & $\begin{array}{l}0.025 \% \text { of reading } \\
0.025 \% \text { of reading } \\
7 \mathrm{~Pa}\end{array}$ \\
\hline $1 \mathrm{P}$ & $\begin{array}{l}P s \_s t a b \\
P d \_s t a b\end{array}$ & $-80^{\circ} \mathrm{C} \leq \mathrm{t} \leq-20^{\circ} \mathrm{C}$ & $\begin{array}{l}\text { Low range } \\
\text { Barometric }\end{array}$ & $\begin{array}{l}5 \mathrm{~Pa} \\
7 \mathrm{~Pa}\end{array}$ \\
\hline
\end{tabular}

Table 7 Uncertainty contributions for temperature and pressure measurements in the HRG, used to determine the CMC

\begin{tabular}{|c|c|c|c|c|}
\hline Mode & $\begin{array}{l}\text { Parameter } \\
\text { (see Table 5) }\end{array}$ & Saturator temperature range & Sensor & Value \\
\hline \multirow[t]{3}{*}{$1 \mathrm{P} / 2 \mathrm{P}$} & $t s \_s t a b$ & $0.3{ }^{\circ} \mathrm{C} \leq \mathrm{t} \leq 100^{\circ} \mathrm{C}$ & $\begin{array}{l}\text { Saturator } \\
\text { temperature }\end{array}$ & $2.0 \mathrm{mK}$ \\
\hline & ts_hom & $\begin{array}{l}0.3{ }^{\circ} \mathrm{C} \leq \mathrm{t} \leq 20{ }^{\circ} \mathrm{C} \\
20{ }^{\circ} \mathrm{C}<\mathrm{t} \leq 90{ }^{\circ} \mathrm{C}\end{array}$ & $\begin{array}{l}\text { Saturator } \\
\text { temperature }\end{array}$ & $\begin{array}{l}5.0 \mathrm{mK} \\
10.0 \mathrm{mK}\end{array}$ \\
\hline & & $90^{\circ} \mathrm{C}<\mathrm{t} \leq 95^{\circ} \mathrm{C}$ & & $15.0 \mathrm{mK}$ \\
\hline \multirow[t]{4}{*}{$2 \mathrm{P}$} & $P s \_s t a b$ & $+0.3{ }^{\circ} \mathrm{C} \leq \mathrm{t} \leq+10^{\circ} \mathrm{C}$ & G1 sat pressure & $0.007 \%$ of reading \\
\hline & Pd_stab & & High range & $0.025 \%$ of reading \\
\hline & & & Low range & $0.5 \%$ of reading \\
\hline & & & Barometric & $7 \mathrm{~Pa}$ \\
\hline \multirow[t]{9}{*}{$1 \mathrm{P}$} & Ps_stab & $+0.3^{\circ} \mathrm{C} \leq \mathrm{t} \leq+20^{\circ} \mathrm{C}$ & G1 sat pressure & $10 \mathrm{~Pa}$ \\
\hline & & & Low range & $5 \mathrm{~Pa}$ \\
\hline & & & Barometric & $7 \mathrm{~Pa}$ \\
\hline & $P d \_s t a b$ & $+20^{\circ} \mathrm{C}<\mathrm{t} \leq+90^{\circ} \mathrm{C}$ & G1 sat pressure & $30 \mathrm{~Pa}$ \\
\hline & & & Low range & $10 \mathrm{~Pa}$ \\
\hline & & & Barometric & $7 \mathrm{~Pa}$ \\
\hline & & $+90^{\circ} \mathrm{C}<\mathrm{t} \leq+95^{\circ} \mathrm{C}$ & G1 sat pressure & $50 \mathrm{~Pa}$ \\
\hline & & & Low range & $15 \mathrm{~Pa}$ \\
\hline & & & Barometric & $7 \mathrm{~Pa}$ \\
\hline
\end{tabular}

The stability is given as one standard deviation and the homogeneity as the gradient obtained from the two temperature measurements 
Table 8 Calibration and measurement capability for primary realization of dew/frost-point temperature

\begin{tabular}{ll}
\hline Frost/dew-point temperature range & Expanded uncertainty, $U(k=2)$ \\
\hline$-90^{\circ} \mathrm{C} \leq \mathrm{t} \leq-80^{\circ} \mathrm{C}$ & $0.40 \mathrm{~K} \ldots 0.20 \mathrm{~K}$ \\
$-80^{\circ} \mathrm{C}<\mathrm{t} \leq-60^{\circ} \mathrm{C}$ & $0.20 \mathrm{~K} \ldots 0.050 \mathrm{~K}$ \\
$-60^{\circ} \mathrm{C}<\mathrm{t} \leq-5^{\circ} \mathrm{C}$ & $0.050 \mathrm{~K}$ \\
$-20^{\circ} \mathrm{C} \leq \mathrm{t} \leq 70^{\circ} \mathrm{C}$ & $0.030 \mathrm{~K}$ \\
$>70^{\circ} \mathrm{C}<\mathrm{t} \leq 90^{\circ} \mathrm{C}$ & $0.040 \mathrm{~K}$ \\
$>90^{\circ} \mathrm{C}<\mathrm{t} \leq 95^{\circ} \mathrm{C}$ & $0.050 \mathrm{~K}$ \\
\hline
\end{tabular}

For ranges, use linear interpolation

sure sensors are offset by half the period to have a recent calibration to ensure the effectiveness of the check between calibrations.

For the LRG, the contributions for the effect of the tubing due to desorption (Ps_tub and $P d \_t u b$ ) are estimated as $1 \mathrm{mK}$ down to $-60^{\circ} \mathrm{C}$, increasing to $50 \mathrm{mK}$ at $-80^{\circ} \mathrm{C}$ and to $200 \mathrm{mK}$ at $-90{ }^{\circ} \mathrm{C}$, equivalent to values of standard uncertainty $(k=1)$ of $<1 \mathrm{mK}$, $14 \mathrm{mK}$ and $58 \mathrm{mK}$, respectively. The saturation efficiency is determined experimentally in terms of dew-point temperature from the variations in the generated dew-point temperature in the operating range of pre-saturator temperature and flowrate. This contribution has a best estimate of zero under the operational conditions defined in Tables 6 and 7 for the LRG and HRG, respectively, and is covered by the contribution assigned to the reproducibility of the DPMs used in the evaluation. The resulting CMC is given in Table 8 and is equal to that published in [2].

In accordance with established good practice, the generator is always operated with a monitoring transfer standard hygrometer, MBW 373LX or MBW 373HX, for the low- and high-range generators, respectively. The contribution due to the dew-point temperature stability and the maximum allowable difference from the current calibration (using the same standard humidity generator) of the monitoring transfer standard hygrometers of the two generators are given in Table 9, as a function of frost/dew-point temperature. This check with respect to the monitoring transfer standard is a redundant quality control feature, aimed at providing confidence in the generated value, and detecting any anomalous performance of the generator at the time of measurement. It is also representative of the achievable limit of repeatability and reproducibility of a unit under test of the highest metrological quality, for determination of the CMC that the laboratory has experience with.

The established limits are used as the input quantities in the uncertainty budget for the determination of the declared CMC, in accordance with [14-16].

\subsection{Comparison with an Externally Calibrated DPM}

To assess the possibility of any systematic difference in the realized frost/dew-point temperature realization using the new generators, externally calibrated DPMs were used as transfer standards and calibrated using the new generators. 
Table 9 Individual contribution of uncertainty due to the repeatability of the transfer standard hygrometer $(k=1)$ used to monitor the generator output, and the estimated combined reproducibility of the generator and transfer standard (twice the semi-interval), used as acceptance criteria relative to its current calibration with the same standard under conditions of negligible long-term stability) used to check the optimum performance of the generators at the time and conditions of use

\begin{tabular}{lll}
\hline Frost/dew-point temperature range & Repeatability $(\mathrm{K})$ & Combined reproducibility $(\mathrm{K})$ \\
\hline$-90{ }^{\circ} \mathrm{C} \leq \mathrm{t} \leq-80^{\circ} \mathrm{C}$ & 0.10 & 0.06 \\
$-80^{\circ} \mathrm{C}<\mathrm{t} \leq-60^{\circ} \mathrm{C}$ & 0.05 & 0.07 \\
$-60{ }^{\circ} \mathrm{C}<\mathrm{t} \leq-20^{\circ} \mathrm{C}$ & 0.015 & 0.03 \\
$-20{ }^{\circ} \mathrm{C} \leq \mathrm{t} \leq+20^{\circ} \mathrm{C}$ & 0.003 & 0.01 \\
$+20{ }^{\circ} \mathrm{C}<\mathrm{t} \leq+90^{\circ} \mathrm{C}$ & 0.005 & 0.01 \\
$+90^{\circ} \mathrm{C}<\mathrm{t} \leq+95^{\circ} \mathrm{C}$ & 0.007 & 0.015
\end{tabular}

These values are used as the contributions of the DPM being calibrated with the standard humidity generator to determine the CMC

$\triangle$ NPL 2011 A NPL 2012 NPL 2015 - MBW 2016

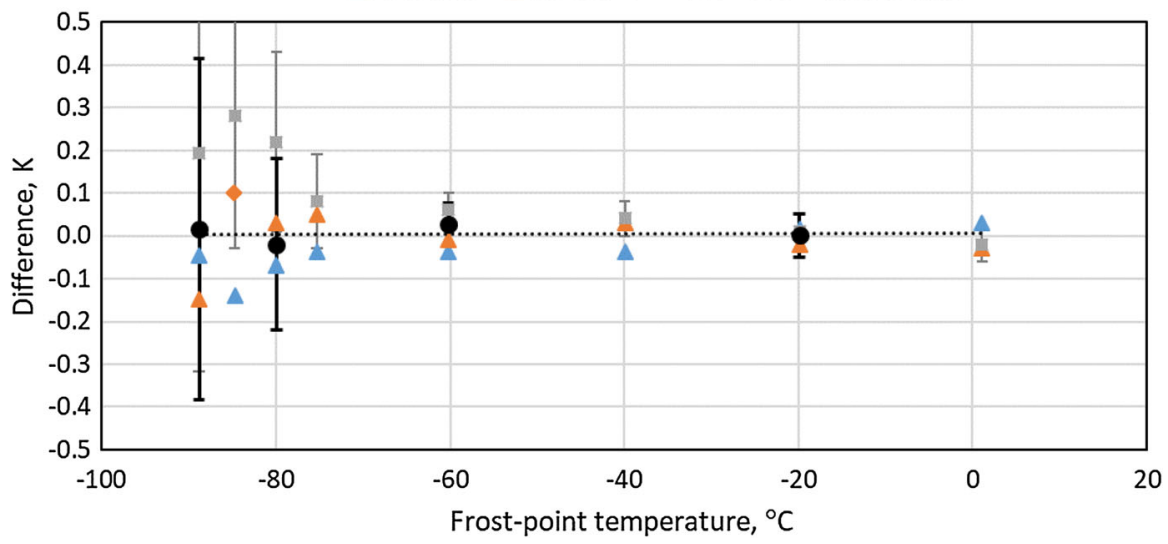

Fig. 17 Difference between calibration of monitoring transfer standard MBW 373LX SN 11-0190 at MBW and NPL. Baseline is average of NPL calibrations

\subsubsection{Low-Range Generator}

The difference between the calibration results of the second platinum resistance thermometer (PRT) embedded in the mirror for instrument MBW 373LX SN 11-0106, obtained at MBW and the previous three calibrations at NPL are depicted in Fig. 17. The baseline is the average of the three NPL calibrations. As can be seen there is a larger irreproducibility at the low end. The error bars are the MBW and NPL CMCs for a confidence level of approximately $95 \%$. The results show an excellent agreement with differences of $1 \mathrm{mK}$ at $-20{ }^{\circ} \mathrm{C}, 26 \mathrm{mK}$ at $-60{ }^{\circ} \mathrm{C},-20 \mathrm{mK}$ at $-80{ }^{\circ} \mathrm{C}$ and $+15 \mathrm{mK}$ at $-90^{\circ} \mathrm{C}$. 


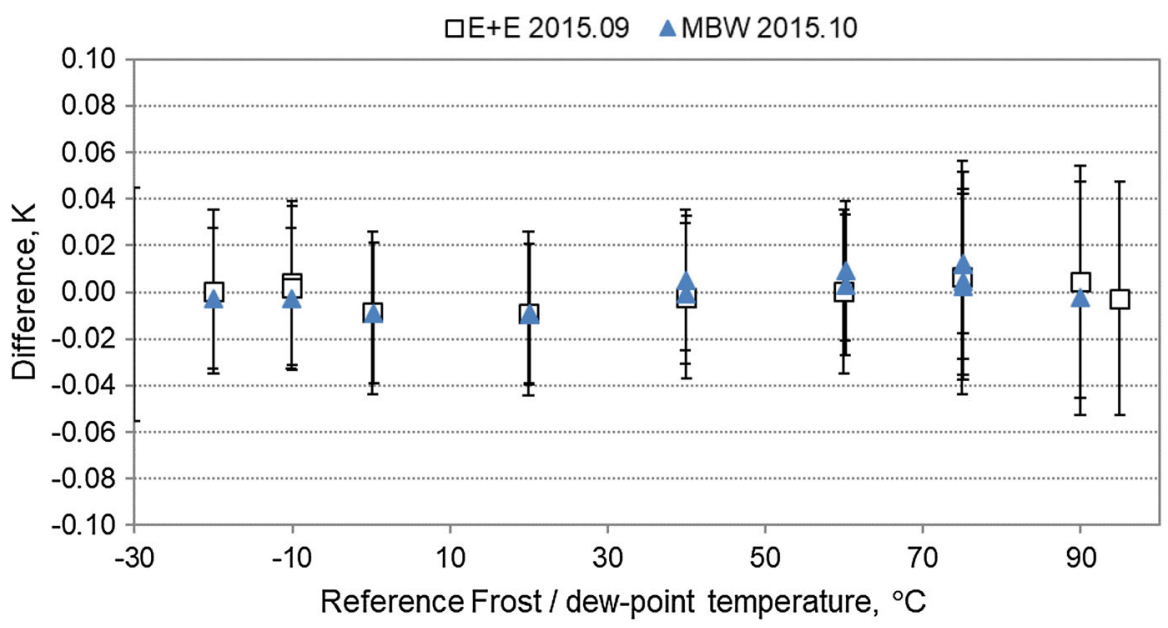

Fig. 18 Difference between calibration of monitoring transfer standard MBW 373HX SN 09-0724 at MBW in 2015.10 and $\mathrm{BEV} / \mathrm{E}+\mathrm{E}$ in 2015.09

Table 10 Comparison of HRG (2P) and LRG (1P) at $-20{ }^{\circ} \mathrm{C}$ frost point

\begin{tabular}{llll}
\hline Transfer standard serial number & $\begin{array}{l}\text { Correction } \\
\text { HRG }(\mathrm{mK})\end{array}$ & $\begin{array}{l}\text { Correction } \\
\text { LRG }(\mathrm{mK})\end{array}$ & $\begin{array}{l}\text { Difference } \\
\text { HRG-LRG }(\mathrm{mK})\end{array}$ \\
\hline $11-0190$ & +35.5 & +34.4 & -1.1 \\
$12-0601$ & +36.5 & +28.0 & -8.1 \\
\hline
\end{tabular}

\subsubsection{High-Range Generator}

The difference between the calibration results of the second PRT embedded in the mirror for instrument MBW 373HX SN 09-0724, obtained at MBW and BEV/E+E in September and October 2015, is depicted in Fig. 18. The error bars are the MBW and $\mathrm{E}+\mathrm{E}$ CMCs for a confidence level of approximately $95 \%$. The results show an excellent agreement to within $\pm 5 \mathrm{mK}$ in the range from $-20{ }^{\circ} \mathrm{C}$ to $+90^{\circ} \mathrm{C}$.

\subsubsection{Comparison Between Generators}

A comparison of the HRG in two-pressure mode and the LRG in single-pressure mode at $-20^{\circ} \mathrm{C}$ frost point was performed with two MBW $373 \mathrm{LX}$ transfer standards (see Table 10), giving a difference of less than $10 \mathrm{mK}$ between the instrument corrections for the HRG and LRG generators. This result is highly satisfactory.

\section{Conclusions}

The design, construction and validation of two standard humidity generators to be used as the Swiss national standard for the primary realization of dew-point temperature in 
the range from $-90{ }^{\circ} \mathrm{C}$ to $+95^{\circ} \mathrm{C}$ have been presented and discussed. The low-range generator is operated as a continuous flow "single-pressure" generator in the range from $-80^{\circ} \mathrm{C}$ to $-10^{\circ} \mathrm{C}$ and as a "two-pressure" generator for frost-point temperatures down to $-90^{\circ} \mathrm{C}$ for flowrates up to $5 \mathrm{~L} \cdot \mathrm{min}^{-1}$. The high-range generator is used as a continuous flow "single-pressure" generator in the range from $0.3{ }^{\circ} \mathrm{C}$ to $95{ }^{\circ} \mathrm{C}$ and as a "two-pressure" generator for frost-point temperatures down to $-20^{\circ} \mathrm{C}$ for flowrates up to $5 \mathrm{~L} \cdot \mathrm{min}^{-1}$. The high-range generator includes a proprietary totally automated pre-saturation and flow control system that facilitates the calibration of state-of-the-art chilled-mirror transfer for standards without the need for manual readjustment of the generated flowrate to ensure a constant volumetric flow at the conditions of the transfer standard mirror.

The validation tests performed to ensure the saturation efficiency have been discussed, and the results show that the generator constitutes a stable and reproducible primary realization of frost/dew-point temperature in the range investigated.

The uncertainty budget leading to the CMC for frost/dew-point temperature realization has been presented, and the generated values of frost/dew-point temperatures have been compared over the range from $-90{ }^{\circ} \mathrm{C}$ to $+95^{\circ} \mathrm{C}$ with the external calibration of an MBW transfer standard obtained at an NMI and DI using their published CMCs under the CIPM-MRA. The generators have also been compared at their overlapping frost-point of $-20^{\circ} \mathrm{C}$, showing the consistency of both realizations.

Open Access This article is distributed under the terms of the Creative Commons Attribution 4.0 International License (http://creativecommons.org/licenses/by/4.0/), which permits unrestricted use, distribution, and reproduction in any medium, provided you give appropriate credit to the original author(s) and the source, provide a link to the Creative Commons license, and indicate if changes were made.

\section{References}

1. ISO/IEC 17025:2005 General requirements for the competence of test and calibration laboratories

2. Scope of accreditation number SCS 0125. Swiss Accreditation Service SAS, SCS Directory. See www. sas.admin.ch (Accredited bodies). Revision F. Last visited on 07 May 2017

3. H. Mitter, The BEV/E + E Elektronik standard humidity generator, in 5th Int. Symposium on Humidity and Moisture-ISHM2006 Brazil May 02-05, Rio de Janeiro (2006)

4. H. Kitano, T. Niwa, N. Ochi, C. Takahashi, Saturator efficiency and uncertainty of NMIJ two-pressure two-temperature humidity generator. Int. J. Thermophys. 29, 1615-1622 (2008)

5. C.W. Meyer, W.W. Miller, D.C. Ripple, G.E. Scace, Performance and validation tests on the NIST hybrid humidity generator. Int. J. Thermophys. 29, 1606-1614 (2008)

6. H. Mitter, New BEV/E +E elektronik low-frost-point/high-pressure generator. Int. J. Thermophys. 36, 2242-2258 (2015)

7. Humidity Generator G1 Operating and Maintenance Manual V1.2. MBW Calibration AG (2016)

8. J. Bochsler, Sättiger zu Feuchtegenerator, Bachelor Thesis. University of Applied Sciences and Arts Northwestern Switzerland FHNW (2014)

9. H. Mitter et al., Pressure-drop considerations in the characterization of dew-point transfer standards at high temperatures. Int. J. Thermophys. 33, 1726-1740 (2012)

10. J. Lovell-Smith, On correlation in the water vapour pressure formulations. Metrologia 43, 556-560 (2006)

11. J. Lovell-Smith, An expression for the uncertainty in the water vapour pressure enhancement factor for moist air. Metrologia 44, L49-L52 (2007)

12. B. Hardy, ITS-90 formulations for vapour pressure, frost-point temperature, dew-point temperature and enhancement factors in the range -100 to $100^{\circ} \mathrm{C}$, in Third International Symposium on Humidity and 
Moisture, Papers and Abstracts of the Conference (1998) (National Physical Laboratory), pp. 214-221, ISBN 0946754241

13. D. Sonntag, Advancements in the field of hygrometry. Meteorol. Z. N.E 3, 51-66 (1994)

14. JCGM 100:2008 Evaluation of measurement data-Guide to the expression of uncertainty in measurement

15. EURAMET P 782 MIKES Training Course: Use of a Humidity Generator as a Primary Standard. Martti Heinonen. MIKES (2008)

16. C.W. Meyer, W.W. Miller, D.C. Ripple, G.E. Scace, Uncertainty budget for the nist hybrid humidity generator. Int. J. Thermophys. 33, 1488-1499 (2010) 